\title{
Problems of Friction, Lubrication, and Materials for Rolls in the Rolling Technology*
}

\section{By Ikuo YARIT $A^{* *}$}

\section{Introduction}

To the great advances that our iron and steel industry has achieved despite the two oil crises, the rolling sector contributed such new technologies as hot direct rolling, hot charge rolling, or warm rolling while elevating the quality level remarkably. With regard to rolling of thin gage steels, in particular, (A) raising of rolling speed, (B) high load and heavy reduction rolling to counter the introduction of warm slabs, thicker materials, continuously cast stocks, and thinner products, (C) severer demands for even better quality in terms of surface finish, shape, flatness, and size including the crown and edge drop, (D) adoption of schedule-free rolling to achieve the concatenation and synchronization with steelmaking, (E) introduction of smaller work rolls, and many other have become subjects of intensive research and development.

In meeting those challenges, tribology as applied to between the roll, work, and lubricant, namely those technical problems of friction, lubrication, and wear, have had to be solved one by one together with problems of roll materials. I wish to start this Nishiyama Memorial Seminar, therefore, first by reviewing the theories of lubrication in the thin strip rolling, then surveying the effects of emulsions on rolling lubrication.

Nextly, I intend to discuss various cold rolling lubricants, particularly the trends of developing the mill clean oils and methods of application, then occurrence of rolling defects such as heat streaks, chattering marks, slip marks, as well as lubrication for hot strip rolling.

Finally, I summarize the cares to be exercised in selecting, using, and servicing rolls and the recent trends in developing better materials for rolls.

\section{Review of Theories of Rolling Lubrication}

\section{Classical Theory}

In the classical theory of rolling according to von Karman ${ }^{1)}$ and Orowan, ${ }^{6)}$ the cold rolling is regarded as due to slipping friction ${ }^{7}$ as in Eq. (1) by the Coulomb Law, while the hot rolling is considered as due to sticking friction, ${ }^{8)}$ for which the shear friction equation, Eq. (2), is applied. In either case, the equation of equilibrium is assumed to hold true as shown in Fig. 1. Thus,

$$
\tau_{f}=\mu S
$$

$$
\begin{gathered}
\tau_{f}=k \\
d f / d \phi=2 R^{\prime}\left(S \sin \phi \pm \tau_{f} \cos \phi\right)
\end{gathered}
$$

where, $\tau_{f}$ : the frictional shear stress acting on the boundary

$\mu:$ the friction coefficient

$\phi:$ the angle arbitarily taken within the contact arc

$f:$ the horizontal stress

$k$ : the shear yield strength

$R^{\prime}$ : the radius of the roll as elastically deformed

$S$ : the normal stress.

Though this theory is often good enough to assess friction for mill control, ${ }^{3)}$ it is incapable of predicting behaviors of friction and lubrication, because slipping and sticking may coexist in reality. ${ }^{9)}$

\section{Hydrodynamic Lubrication Theory}

Supposing there exists an oil film in the contact arc to separate the roll and the material, we can set up following equations to describe the state of affairs shown in Fig. 2, taking $x$ in the direction of rolling. ${ }^{3,4,10)}$

Reynolds equation:

$$
h^{3} / \eta \cdot \partial p / \partial x=-6\left\{(V+U) h-\left(V+U_{0}\right) h_{0}\right\}
$$

Thickness of oil film at the entry region:

$$
h=h_{0}+(x-L) / R
$$

Viscosity equation:

$$
\text { ex., } \quad \eta=\eta_{0} \cdot \exp (\alpha \cdot p)
$$

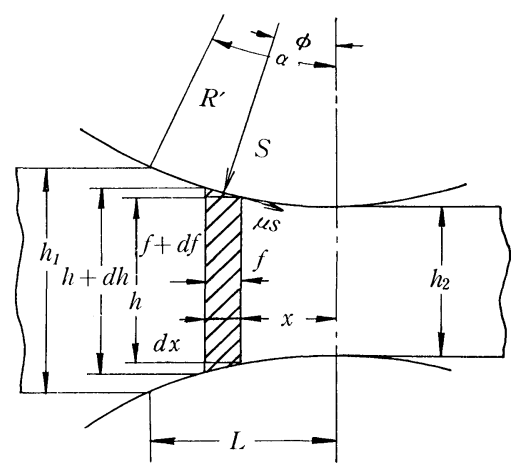

Fig. 1. Balance of forces in rolling according to classical theory due to von Karman.

* Presented to the 92nd-93rd Nishiyama Memorial Seminar, September 1983, at Nokyo Hall in Tokyo and at Osaka Kagaku Gijutsu Center in Osaka. Manuscript received April 17, 1984. (C) 1984 ISIJ

** Research Laboratories, Kawasaki Steel Corporation, Kawasaki-cho, Chiba 260. 


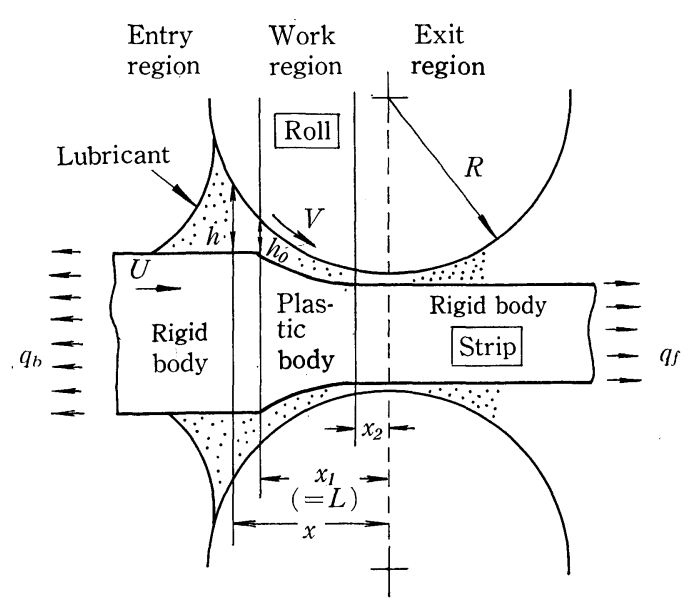

Fig. 2. State of affairs under elastodynamic lubrication.

Navier-Stokes equation:

$$
\tau_{f}=\eta \cdot|V-U| / h
$$

Continuity equation (within the contact arc):

$$
h=h_{0} \cdot\left(V+U_{0}\right) /(V+U)
$$

where, $h$ : the thickness of oil film

$h_{0}$ : the oil film thickness at the entry end of the contact arc

$L:$ the length of the contact arc

$p$ : the pressure of the oil film, which is equal to $S$ within the contact arc

$R:$ the roll radius

$U:$ the velocity of the material

$U_{0}$ : the velocity of the work at the entry end of the contact arc

$V:$ the circumferential velocity of the roll

$u$ : the velocity of the oil film

$\alpha$ : the pressure dependence coefficient of $\eta$

$\eta$ : the viscosity of the oil film

$\eta_{0}$ : the viscosity at ambient pressure

$\tau_{f}$ : the shear stress acting on the oil film.

From those, and in consideration of temperature dependence of viscosity, further, the energy equation can be derived, from which, in turn, the changes in temperature and other dynamic behaviors of oil film may be determined by numerical analysis. ${ }^{4}$ Thus,

$$
\begin{array}{r}
\eta=\eta_{0} \cdot \exp \left\{\alpha_{p}-\beta\left(\frac{1}{T_{0}}-\frac{1}{T}\right)+\gamma \frac{T}{p}\right\} \\
\ldots \ldots \ldots \ldots \ldots \ldots \ldots \ldots \ldots \ldots \ldots \ldots \ldots \ldots \ldots \ldots \ldots \ldots \ldots
\end{array}
$$

This approach is mathematically beautiful, only that in reality, that is to say, from the fact that the roll surface marks are often found printed onto the material surface, the unfailing upholding of hydrodynamic lubrication condition in actual rolling is unlikely.

\section{3. $\quad$ Mixed Lubrication Model}

The mixed lubrication model was devised to accommodate those theoretical difficulties with reality. ${ }^{5)}$ In this model, lubrication is considered to take the

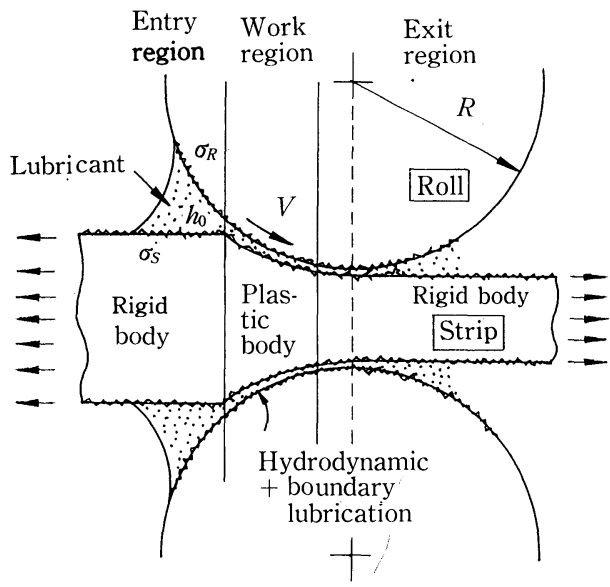

Fig. 3. State of affairs under mixed lubrication.

form of either hydrodynamic or boundary layer according to the relation of oil film thickness to roughness of roll and material. That is to say, for a state of affairs illustrated in Fig. 3, a combined roughness $\sigma$ is defined as in Eq. (11) in consideration of asperities of roll surface, $\sigma_{R}$, and of material surface $\sigma_{S}{ }^{11)}$

$$
\sigma=\sqrt{ } \sigma_{R}^{2}+\sigma_{S}^{2}
$$

Then, in the contact arc, wherever $\sigma$ is larger than the film thickness $h$ as given by Eq. (8), the boundary layer lubrication, i.e., the Coulomb law, is considered to work, whereas when the $\sigma$ is smaller than $h$, Eq. (7), i.e., the hydrodynamic lubrication, is in action. Here, the proportion of area where the boundary layer lubrication is at work, $A$, may generally be determined statistically, in which case the friction shear stress $\tau$ is given by

$$
\tau=A \cdot \tau_{b}+(1-A) \tau_{f}
$$

where, $\tau_{b}=\mu_{b} \cdot S$ (region of boundary layer lubrication)

$\tau_{f}=\eta|V-U| / h$ (region of hydrodynamic lubrication).

The rolling pressure distribution along the contact arc is shown for the hydrodynamic lubrication in Fig. 4,4) and for the mixed lubrication in Fig. 5.12) It will be seen that this model appears to give an agreeable representation of actual state of affairs existing in the contact arc region and to allow reasonable deduction of friction and lubrication with regard to the effects of the roll surface roughness and of the lubricant.

\section{Characteristics of Rolling Lubricants}

\section{Dynamics of Emulsion Flow}

Emulsions of $\mathrm{O} / \mathrm{W}$ (oil-water mixture) type are generally used today for rolling lubricant. The peculiarity of emulsion lubricants is that, as may be seen in Fig. 6, when sprayed out of a nozzle and plating on the material, the emulsion lets its oil component separated out onto the material surface, excluding the water component. This is known by 
Case I: The case of no lubrication (Friction coefficient, 0.05)

Case II: The case of hydrodynamic lubrication

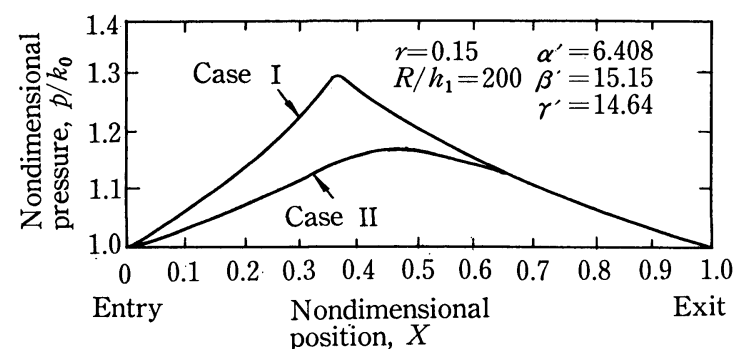

$r$ : reduction $R:$ roll diameter

$h_{1}$ : entering material thickness

$\alpha^{\prime}$ : dimensionless pressure-viscosity exponent

$\beta^{\prime}$ : dimensionless temperature-viscosity exponent

$\gamma^{\prime}$ : dimensionless pressure-temperature-viscosity exponent

$p$ : pressure acting within the contact arc region

$k_{0}$ : effective yield stress

Fig. 4. Comparison of rolling pressure distribution between hydrodynamic lubrication and dry friction. ${ }^{4)}$

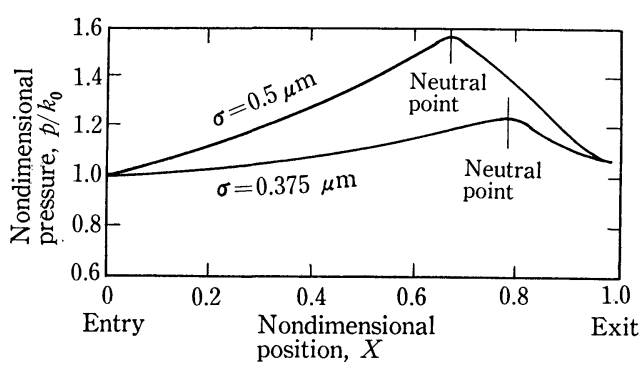

Fig. 5. Effects of the combined roughness $\sigma$ on the rolling pressure computed on the mixed lubrication model.12)

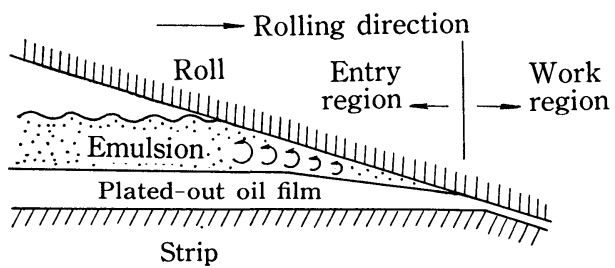

Fig. 6. Dynamics of oil film formation under emulsion lubrication.

the term "plating out".

Further, in the entry region of the contact arc where the EHL (elasto-hydrodynamic lubrication) operates, a research paper has $\mathrm{it}^{13)}$ that a layer of emulsion is drawn into hydrodynamic lubricationwise over the plated-out oil layer by wedging effect. Here, under the increased pressure at between the roll and work, phase transition (ex., $\mathrm{O} / \mathrm{W}$ to $\mathrm{W} / \mathrm{O}$ ) takes place with a result that a high concentration emulsion is drawn into the contact portion.

This is seen in Fig. 7, where relations between the contents of emulsifier and the thickness of oil film are presented by the content of oil (the base oil being a mineral oil) as determined by means of EHL experimentation. It will be seen that in the range of little

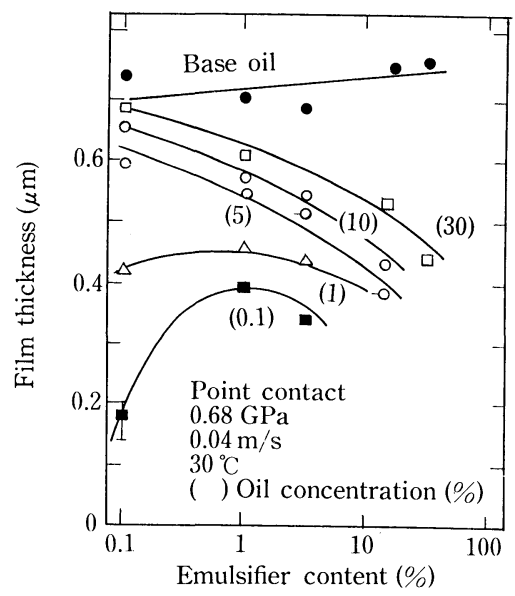

Fig. 7. Effects of intensified emulsification on the oil film thickness as determined by EHL experimentation.

emulsifier, such as the cases of ordinary rolling oils, an oil concentration of as little as $5 \%$ will ensure an oil film almost as thick as the base oil. Therefore, it may be said that $\mathrm{O} / \mathrm{W}$ type emulsion will develop in rolling these oil films that the base oil itself will develop under similar conditions. This will mean in turn that physical properties of the base oil may be used in the viscosity equation without incurring much error.

\section{Thickness of In-flowing Oil Film}

In the viscosity equation (6), when only the pressure dependency is considered, the entry end oil film thickness $h_{0}$ may be expressed as

$$
h_{0}=3 \eta_{0} \alpha R \cdot\left(U_{0}+V\right) /(1-\exp (-\alpha p)) \cdot L
$$

Here, for ordinary rolling oils, as $\alpha=0.1$ to 0.01 and $p=50$ to $200 \mathrm{~kg} / \mathrm{mm}^{2}$, the $1-e^{-\alpha p}$ term is nearly equal to unity, hence $\eta_{0}$ and $\alpha$ affect $h_{0}$ linearly.

When the influence of temperature is taken into consideration, however, the oil film thickness $h_{0}$ will suffer a drastic decrease as may be calculated by Eqs. (9) and (10). This is shown in Fig. 8, ${ }^{14)}$ where it will be seen that $h_{0}$ is greatly reduced in thickness by the thermal effect. In an operating mill, further, it has been reported that $h_{0}$ became maximum at a roll circumferential velocity of some $600 \sim$ $800 \mathrm{~m} / \mathrm{min}^{.12)}$

Figures 9 to 11 illustrate the influences of the terms $\eta_{0}, \alpha$, and $\beta$ on $h_{0}$ when the viscosity is given by $\eta=\eta_{0} \cdot \exp (\alpha p-\beta T) .^{15)}$ Also, it may well be that roughness of the roll surface and of the work surface affect the oil film thickness.

\section{Emulsion Particle Diameter Distribution and Rolling Force}

In Fig. 12, relations between the distribution of particle diameters in an emulsion as measured by the coulter counter and the rolling forces per unit width are shown. ${ }^{16)}$ It will be seen that overly large or overly small particles both cause the rolling force to increase. For this, an EDPI (emulsion dis- 
tribution profile index) has been proposed as in Eq. (14);

$$
\mathrm{EDPI}=\frac{\begin{array}{l}
\text { Equivalent occupancy area for } \\
\text { diameters } 5 \sim 10 \mu \mathrm{m}
\end{array}}{\begin{array}{l}
\text { Equivalent occupancy area for } \\
\text { diameters } 1 \sim 5 \mu \mathrm{m}
\end{array}}
$$

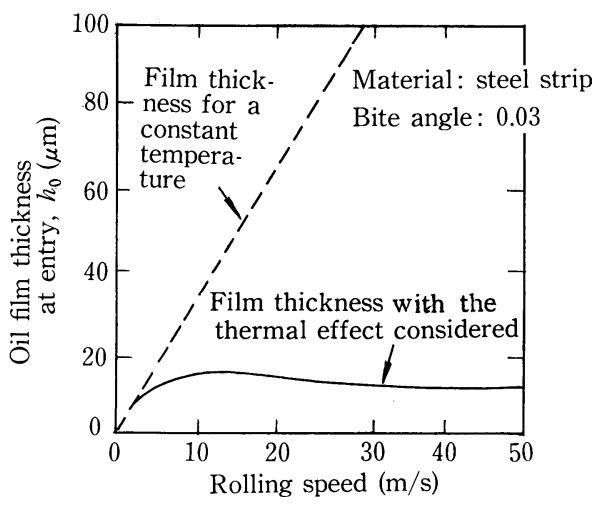

Fig. 8. Effects of rolling speed on the entry oil film thickness as computed by the hydrodynamic lubrication theory.
The effects of emulsifier are shown in Fig. 13 in terms of relations between EDPI and the amount of plated-out oil, and in Fig. 14 for relationship between

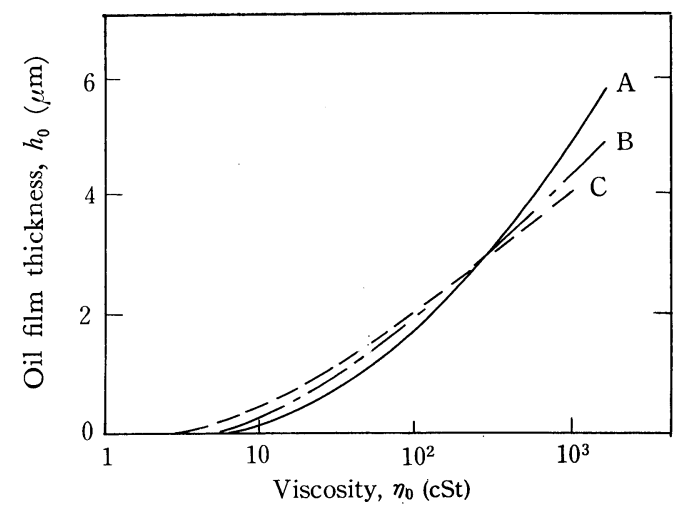
A : $\quad \eta=\eta_{0} e^{0.001 p} \cdot e^{-0.02(T-50)}$
$\mathrm{C}: \quad \eta=\eta_{0} e^{0.003 p} \cdot e^{-0.06(T-50)}$
B : $\quad \eta=\eta_{0} e^{0.002 p} \cdot e^{-0.04(T-50)}$

Roll dia.: $580 \mathrm{~mm} \phi \quad$ Sheet thickness : $0.35 \mathrm{~mm}$ Reduction: $30 \% \quad$ Flow stress : $40 \mathrm{~kg} / \mathrm{mm}^{2}$ Rolling speed: $1000 \mathrm{~m} / \mathrm{min}$

Fig. 9. Effects of ambient temperature, ambient pressure viscosity $\eta_{0}$ on the oil film thickness $h_{0}$ as calculated by the hydrodynamic lubrication theory.

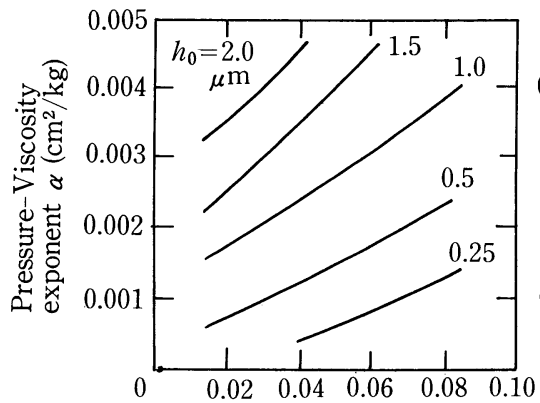

(a) $500 \mathrm{~m} / \mathrm{min}$ $\eta_{0}=50 \mathrm{cSt}$, Reduction: $30 \%$

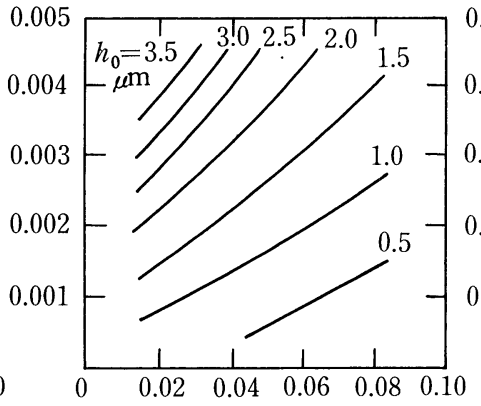

Temperature-Viscosity exponent $\beta\left(1 /{ }^{\circ} \mathrm{C}\right)$

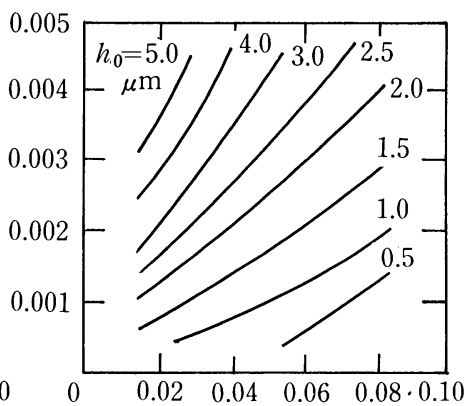

(b) $1000 \mathrm{~m} / \mathrm{min}$

(c) $2000 \mathrm{~m} / \mathrm{min}$

Roll dia.: $580 \mathrm{~mm} \phi$

Flow stress : $40 \mathrm{~kg} / \mathrm{mm}^{2}$

Sheet thickness: $0.35 \mathrm{~mm}$

Fig. 10. Changes in relations of temperature dependence or pressure dependence of viscosity $v s$. oil film thickness as a function of rolling speed as calculated by the hydrodynamic lubrication theory.

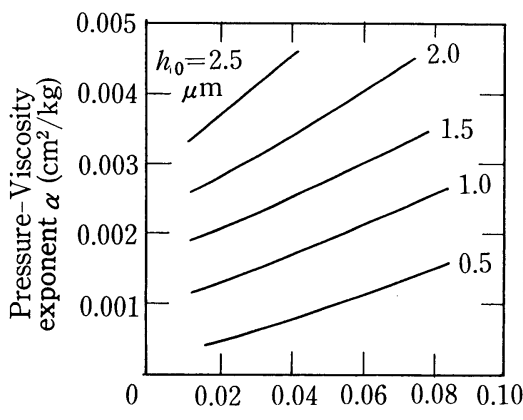

(a) $\eta_{0}=25 \mathrm{cSt}$

Rolling speed: $1000 \mathrm{~m} / \mathrm{min}$ Reduction: $30 \%$
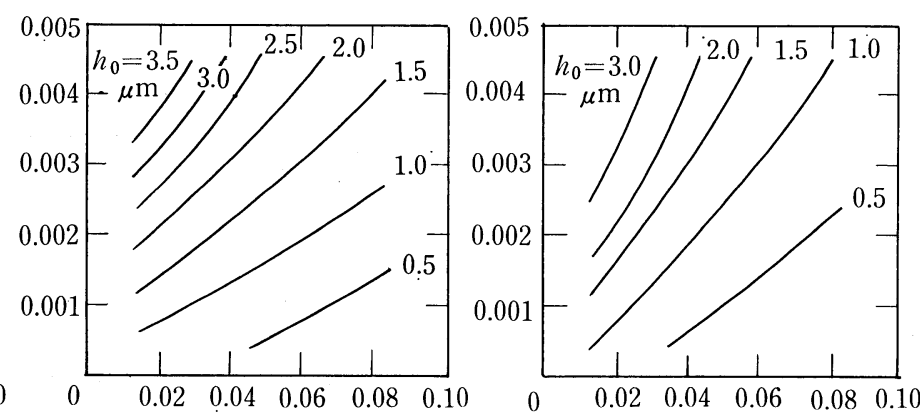

Temperature-Viscosity exponent $\beta\left(1 /{ }^{\circ} \mathrm{C}\right)$

(b) $\eta_{0}=50 \mathrm{cSt}$

Roll dia.: $580 \mathrm{~mm} \phi$

Flow stress: $40 \mathrm{~kg} / \mathrm{mm}^{2}$

Fig. 11. Changes in relations of temperature dependence or pressure dependence of viscosity $v s$. oil film thickness as a function of ambient viscosity as calculated by the hydrodynamic lubrication theory. 


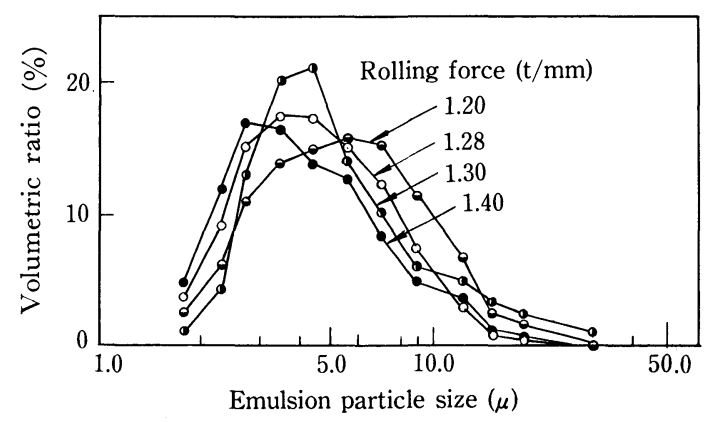

Fig. 12. Effects of emulsion particle distribution on rolling force.

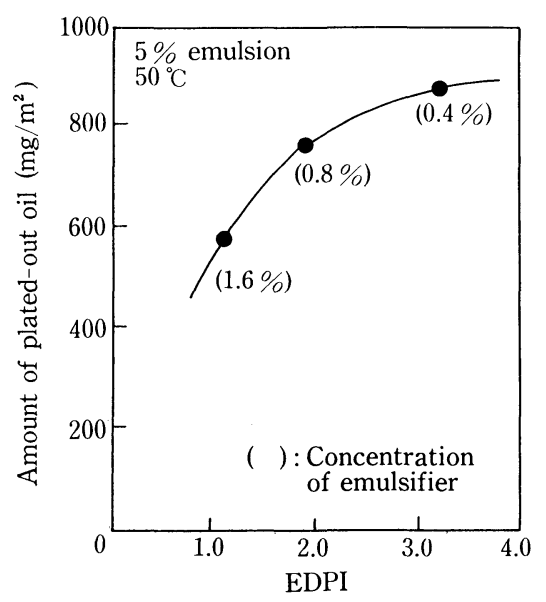

Fig. 13. Relationship between EDPI and amount of oil plated out onto the work surface.

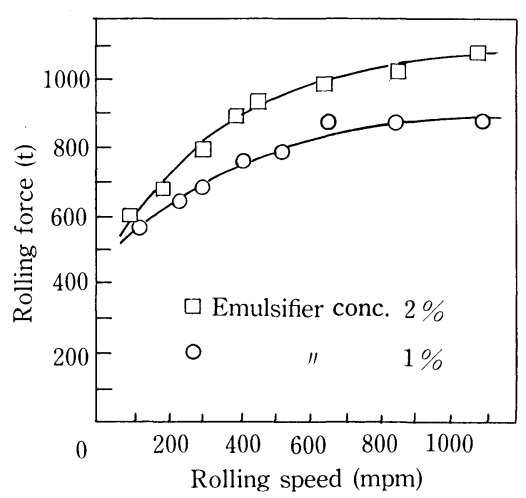

Fig. 14. Relationship between concentration of emulsifier and rolling force.

the rolling speed and the rolling force. ${ }^{17)}$ They demonstrate how it is important to select proper particle size profile for a rolling condition given. In this respect, the polymer dispersers are expected to improve the situation greatly, ${ }^{18,19)}$ for those reagents will stabilize the emulsion as finely dispersed by their ability of colloid-making and secondary coagulation, so much so that, as shown in Fig. 15, the particle size may be controlled at will by, for example, changing the revolution speed of the mixer, thus, modifying the dispersion.

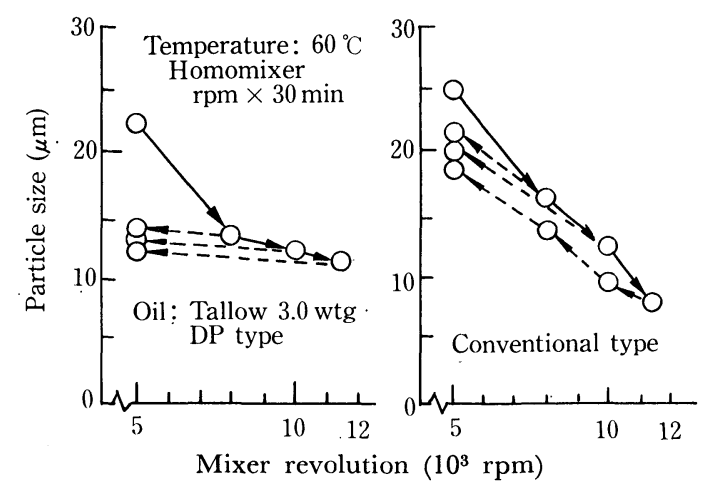

Fig. 15. Effect of addition of disperser on the relationship between emulsion particle diameter and revolutional speed of mixer.

\section{Lubricants for Cold Rolling}

\section{Application of Rolling Oil}

The methods of applying rolling oil may be divided into the direct spraying system and the recirculatory spraying system. In the first, the high concentration emulsion is directly sprayed onto the material, while the cooling water is sprayed onto the roll through separate line. For the rolling oil, palm oil is used most popularly. It is recovered after separating water, and reapplied mainly to the fore stands of tandem mill. Though rather high in the per rolled steel tonnage consumption, this type of usage is often employed for thin gages, such as strips for tin plate and galvanized sheet, because of its high lubricity and of the need of stabilizing the surface quality.

In the recirculatory spraying system, on the other hand, a low concentration emulsion is sprayed onto the roll as well as to the rollbite so as to function both as lubricant and as roll coolant. Mineral oils, tallows, synthetic esters, and the like are the popular ones, and it is particularly important for this method not to make the emulsion age by keeping the concentration and emulsification constant at the reservoir tank, for the emulsion is expected to be used for a long time.

There is yet another system, which appears to hold a good prospect of attaining all of high lubricity, high cooling, and low consumption by combining good points of the direct spraying method and the recirculatory method. It is called the hybrid method ${ }^{20)}$ which is, as may be seen in Fig. 16, consisted of the hybrid line that is the small mixing tank and the recirculation line that is the large reservoir tank. That is to say, in the mixing tank, a small amount of fresh oil is fed to make up a relatively thick emulsion, which is sprayed either onto the material or into the rollbite to ensure a high grade lubrication, while in the large tank, makeup water is supplied to hold a cool and thin emulsion to be used as the roll coolant.

The effects of this hybrid method are shown in Fig. 17 for tallow in terms of the changes in the rolling force. It will be noted that lubrication may be controlled better by controlling the flow rate of 


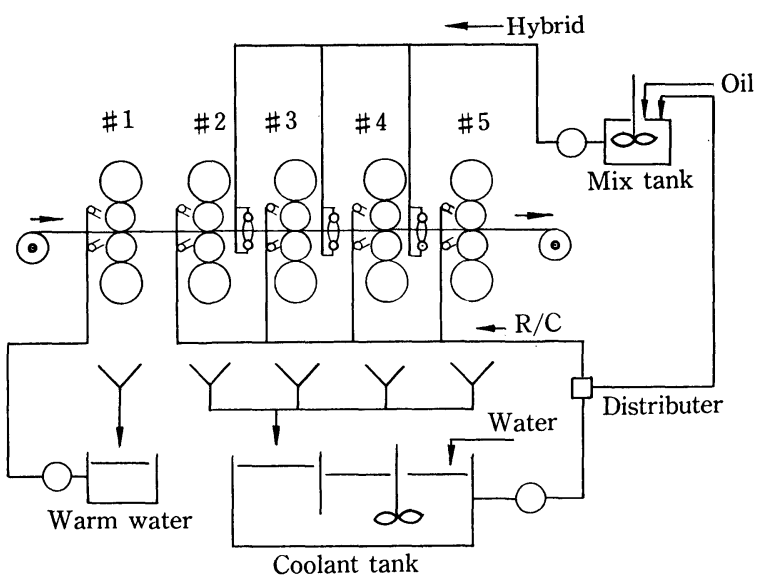

Fig. 16. System diagram of the hybrid lubrication method.

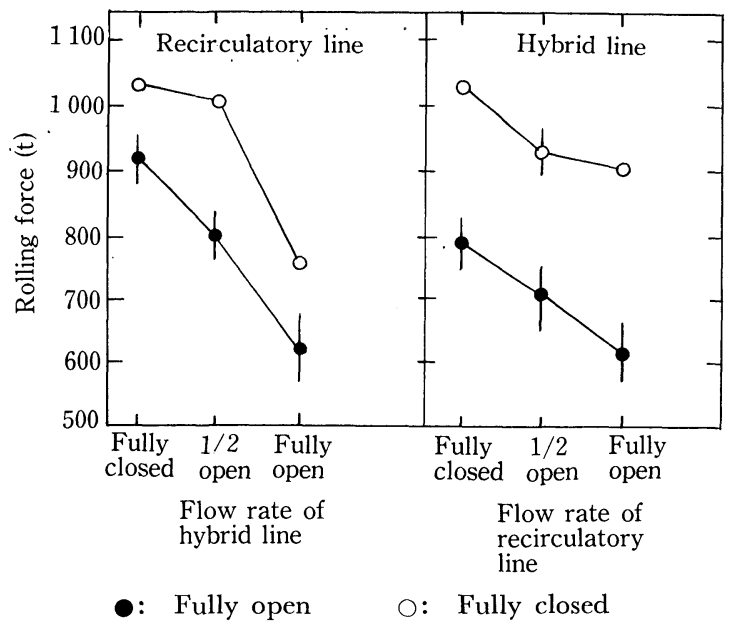

Fig. 17. Functions of hybrid line and recirculatory line in the hybrid lubrication system with tallow type oil.

the hybrid line. Also, it is reported that the oil consumption is decreased to about one half of what used to be with the conventional recirculatory system.

Further, the hybrid system is compared with the recirculatory system in Fig. 18 by the relation between coolant temperature and steam consumption: the hybrid is noted for its lower coolant temperatre and markedly smaller steam consumption.

\section{Kinds and Properties of Rolling Oils}

\section{Palm Oil}

The palm oil is most common for rolling thin gage strips for galvanizing or tinning, and is used usually in the direct application mode. The major component is a natural ester composed, as represented by Eq. (15), of fatty acid of stearine acid or oleic acid type and of glycerine:

$$
\begin{gathered}
\mathrm{H}_{2}-\mathrm{C}-\mathrm{O}-\stackrel{\mathrm{I}}{\mathrm{C}}-\mathrm{R}_{1} \\
\stackrel{\mathrm{O}}{\mathrm{II}} \\
\mathrm{H}_{2}-\mathrm{C}-\mathrm{O}-\stackrel{\mathrm{C}}{\mathrm{C}}^{\mathrm{O}}-\mathrm{R}_{2} \\
\stackrel{\mathrm{O}}{\mathrm{H}_{2}-\mathrm{C}-\mathrm{O}-\mathrm{I}-\mathrm{C}-\mathrm{H}_{3}}
\end{gathered}
$$

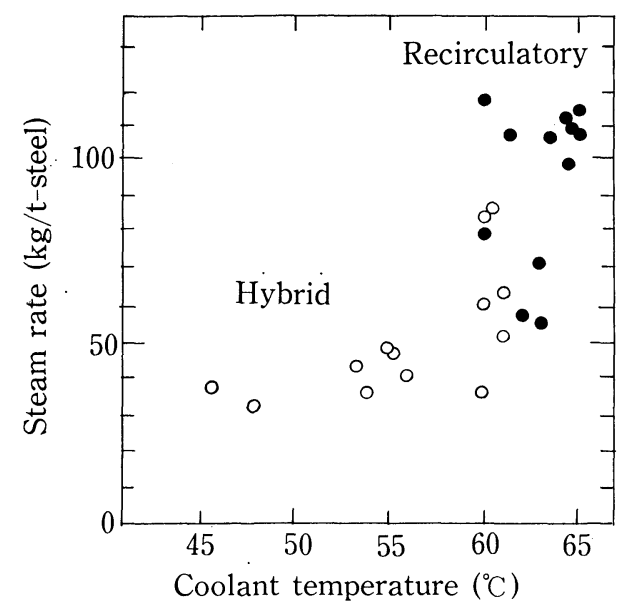

Fig. 18. Comparison of steam consumption between hybrid lubrication method and recirculatory lubrication method.

where $R_{1}, R_{2}$, and $R_{3}$ are alkyl radicals, mostly of $\mathrm{C}_{18}$ and $\mathrm{C}_{18 F_{1}}$, such that $\mathrm{G}_{18}: \mathrm{C}_{18 F_{1}}=1: 2$.

This is because the proven high lubricity and high cooling of the palm oil is well suited for high speed rolling, which is over $2000 \mathrm{~m} / \mathrm{min}$ in the case of tin plates, as well as for recent tendency toward yet thinner gages. For those purposes, instances of using a $P$ type extreme pressure additive to improve lubrication further are becoming used.

\section{High Lubricity Oil}

Tallows or fatty acid type synthetic esters, rather than expensive palm oil, are used in rolling for galvanizing and thin sheet-gage steels in the recirculatory mode. The composition of tallow is like Eq. (15), except the ratio of stearine acid to oleic acid is nearly one to one. To improve the lubrication still more, an oiliness agent (mostly a high order fatty acid) or an extreme presure additive is often added. To ensure a long term usage, further, selection of proper emulsifier is important to stabilize the emulsion at an appropriate size profile.

\section{The Mill-clean Oil}

Unlike the cases of open annealing or continuous annealing, if the sheet-gage stock is to be submitted to tight coil annealing as cold rolled, i.e., omitting cleaning, dirts, such as carbon remaining on the surface or edges, or other impurities can be detrimental. Here, the rolling oil has traditionally been of either the soluble oil of mineral oil type or the mineral oil and fatty acid mixture type for their weak physicochemical adhesion to the steel and for their high volatility. That is, as may be understood from Eq. (16), since the mineral oil contains no polar radicals, it makes a tight emulsion of not too good plating-out capability and forms a film of rather low strength, so that its lubricity is definitely low.

$$
\begin{aligned}
& \text { Mineral Oil } \begin{cases}\text { Parafines: } & \mathrm{C}_{n} \mathrm{H}_{2 n+2} \\
\text { Naphthene: } & \mathrm{C}_{n} \mathrm{H}_{2 n}\end{cases} \\
& \text { ( } n=12 \text { to } 30)
\end{aligned}
$$

Therefore, when used in rolling of thin gages or for high reduction rates, heat streaking due to rupture 
of oil film under a high temperature, high pressure condition may become problematical.

Here, properties that are required of a mill-clean oil for high speed, high reduction rolling may be:

1) to be able to maintain a high film strength so as not to induce the heat streaks even with a weak cohesion;

2) not to be liable both to thermal decomposition and to polymerization during annealing (those two phenomena can take place simultaneously);

3) to be of a high thermal volatility (namely, of low in the boiling point); and

4) not to be liable to aggravation even if iron particles or iron soap were mixed up in (those will act as catalyst for aging).

From those, development of new mill-clean oils that have as good lubrication as tallows and are as easy to thermally decompose, or clean finishes, as mineral oils are in need. One such product is an oil that is based on a synthetic ester for improved base oil lubricity, added with high polymer fatty acid and high polymer ester of low molecular weight polyole (polyhydric alcohol) for yet better lubricity, and further containing sulfur type anti-oxidation agent for improved mill cleaning. Figure 19 gives the composition of this new rolling oil as well as compares it with two conventional oils by an evaluation test conducted in an operating mill. ${ }^{21}$

Also, there is an oil that is based on a polymeric monoester under appreciation. ${ }^{22}$ ) Then again, in many other practices, a conventional oil like tallow type, synthetic ester type, or mineral oil type is used and detergent is applied to the last stand only.

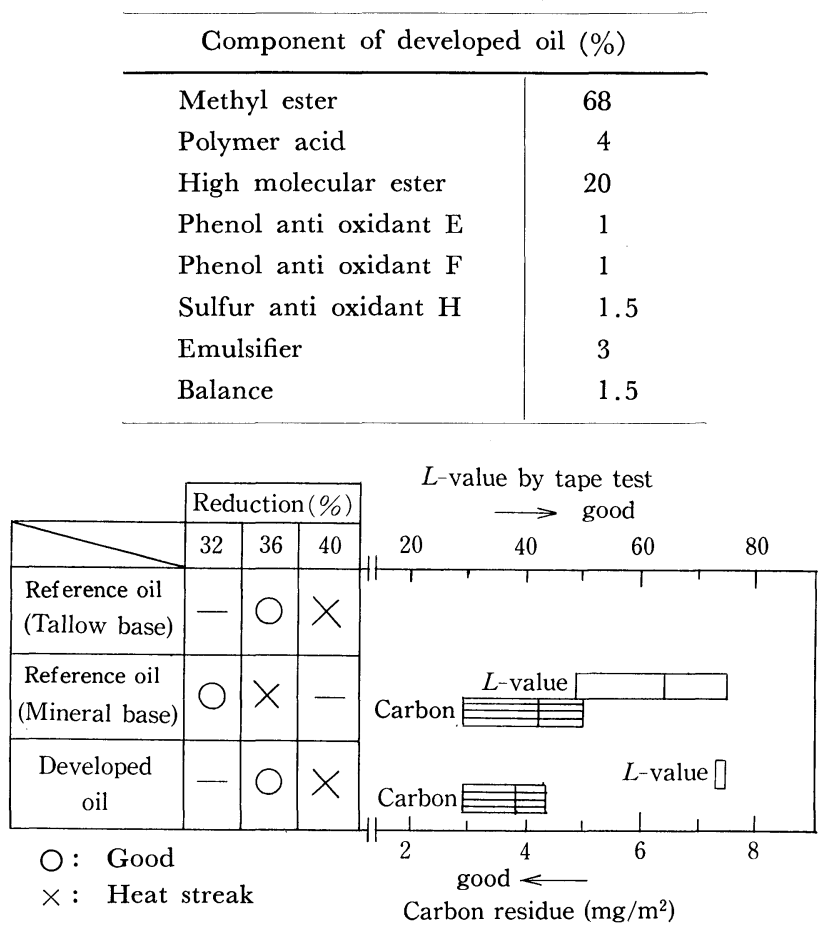

Fig. 19. Contents of a newly developed mill-clean oil and its lubricity and material surface cleanness seen in actual operation.

\section{Defects Related to Lubrication}

Many a faulty rolling has been ascribed to faulty lubrication. The major ones are the heat streaking, the chattering, the slipping, the mottling, the blemishing of work surface due to particles worn out from roll, and the bad shape, of which I wish to discuss the first three here.

\section{Heat Streak}

It is well known that heat streaks are apt to appear under high reduction rate, high speed rolling, with insufficient coolant, and when the roll surface is roughened, because the boundary layer temperature within the contact arc becomes too high.23,24) This is shown in Fig. 20.

As for the mechanisms of occurrence of heat streaks, three forms shown in Photo. 1 have been noted in a confirmation test conducted in an operating mill. The type $\mathrm{A}$, the most common one, appears to initiate, as may be seen in Photo. 2, at one of the roll surface scratches that were made innumerably by dressing. ${ }^{23)}$

The dynamics of this phenomenon has been examined ${ }^{26,27)}$ based on the EHL theory. ${ }^{25}$ ) Here, the problem was reduced to one of elastic rolling contact of an infinite cylinder having an infinitelength scratch on its surface in the axial direction over an infinite plate, where the contact arc was symmetrical about a plane that is perpendicular to the direction of plate advancement (the rolling direction), $x$, and contains the cylinder axis. The computation was done assuming:

1) that a hydrodynamic lubrication oil film exists over the contact arc;

2) that the pressure is constant through the film thickness; and

3) that the width of the roll surface scractch is finite.

The basic equations were as follows:

The pressure-film relationship (Reynolds equation);

$$
h^{3} \cdot d S / d x=6 \eta \cdot(V+U)\left(h-h_{m}\right)
$$

The film thickness equation (geometrical shape plus elastic deformation plus surface scratch);

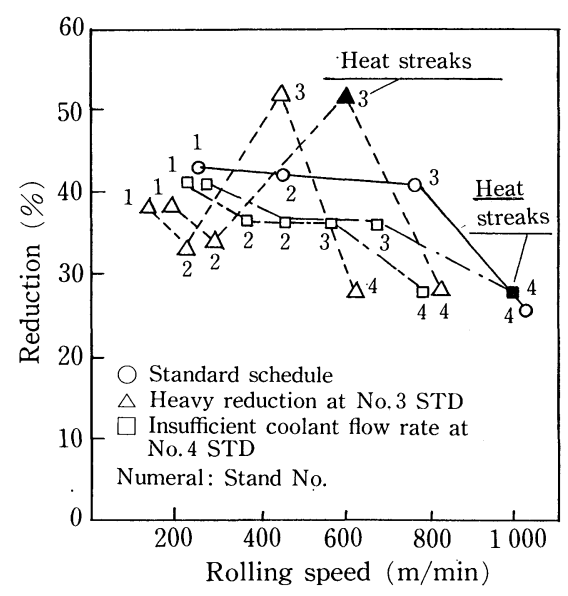

Fig. 20. Appearance of heat streaks in an operational 4stand tandem mill. 


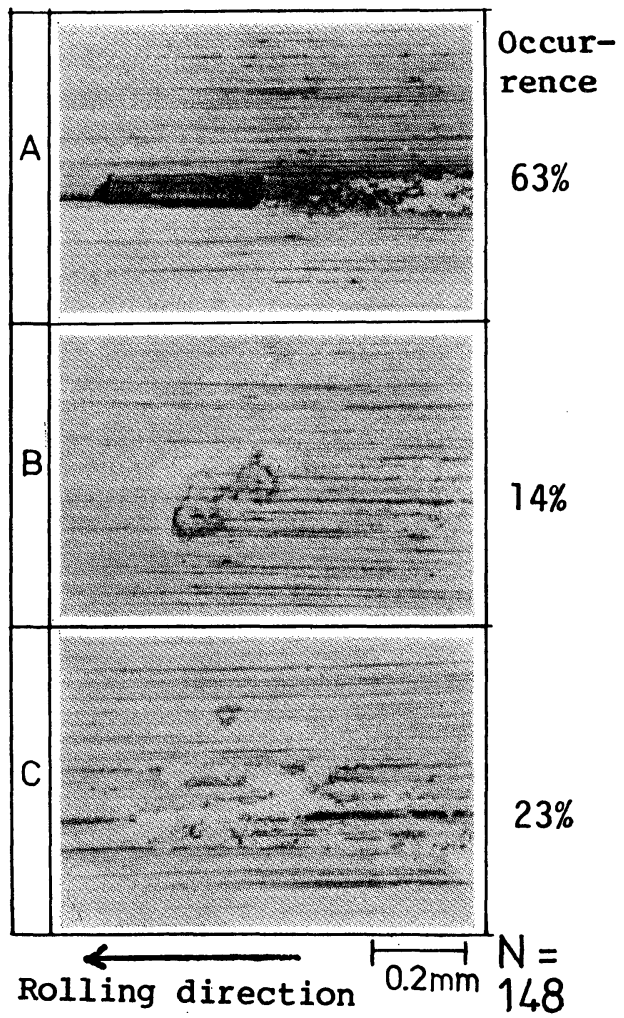

Photo. 1. Examples of initiation of heat streaks as seen on work rolls of an operational mill.

$$
h=h_{0}+x^{2} / 2 R+v+h_{d}
$$

The viscosity of the lubricant;

$$
\eta=\eta_{0} \exp \left\{\alpha S^{n}-\beta\left(\frac{1}{T_{0}}-\frac{1}{T_{m}}\right)\right\}
$$

The elastic deformation;

$$
V=\frac{1}{\pi E_{\mathrm{eq}}} \int_{t_{1}}^{t_{2}} S(t) \ln (x-t)^{2} d t+C_{0}
$$

The rolling force;

$$
W=\int_{t_{1}}^{t_{2}} S(x) d x
$$

The energy equation (heat conduction within the oil film);

$$
\rho_{f} C_{f} u_{f} \frac{\partial T_{f}}{\partial x}-k_{f} \frac{\partial^{2} T_{f}}{\partial y^{2}}=\eta\left(\frac{\partial u_{f}}{\partial y}\right)^{2}
$$

The velocity distribution of the oil film (viscous flow plus pressure difference);

$$
u_{f}=\frac{1}{2 \eta} \frac{d S}{d x}\left(y^{2}-h y\right)+(V-U) \frac{y}{h}+U
$$

where, $C_{0}$ : the integration constant

$C_{f}$ : the specific heat of the oil film

$E_{\text {eq }}$ : the equivalent Young's modulus

$h:$ the film thickness

$h_{0}$ : the film thickness at the center point

$h_{m}$ : the film thickness at the exit

$h_{d}$ : the increment in the oil film thickness due to roll surface scratch

$k_{f}$ : the heat conductivity of the film

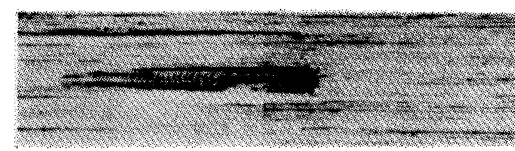

before rolling

Roll

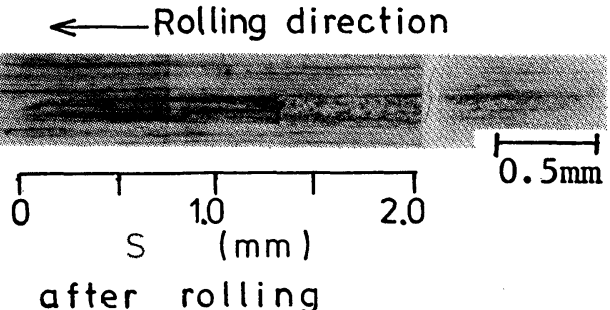

after rolling

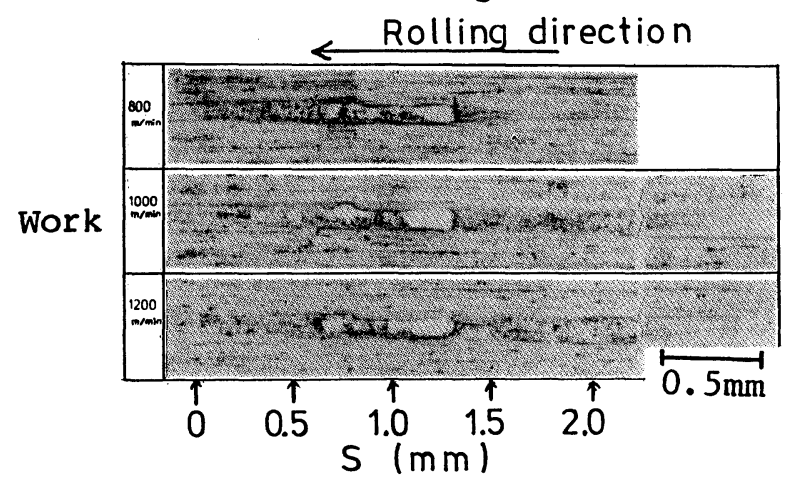

Photo. 2. Heat streaks generated at scratches made upon dressing.

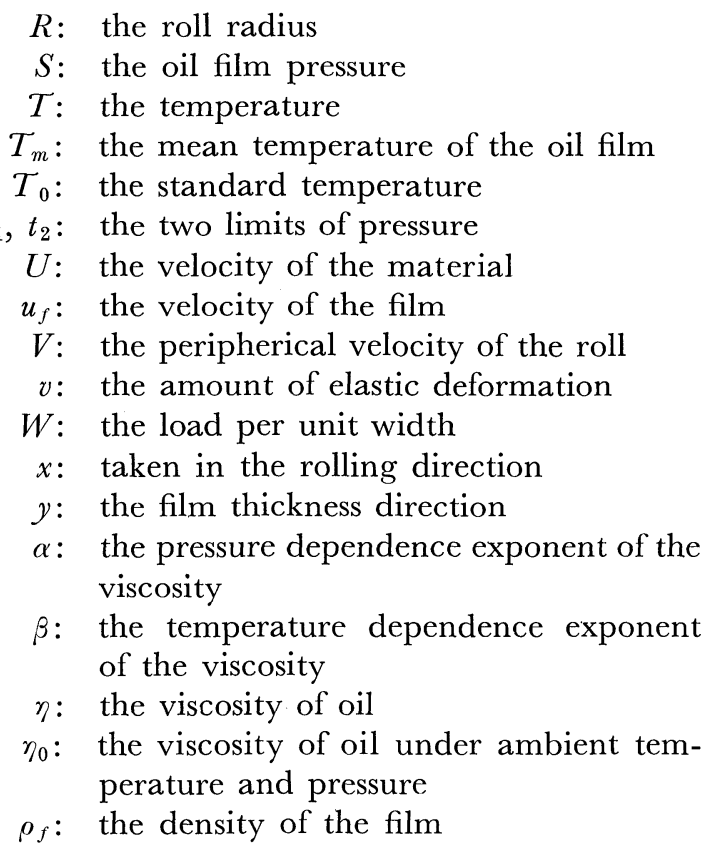

Some of the results have been summarized in Figs. 21 and 22. In Fig. 21, effects a roll surface scratch ( $1 \mathrm{~mm}$ long and $10 \mu \mathrm{m}$ deep) exerts on pressure and temperature of the oil film are shown. It will be seen that at the either end of the scratch the oil film is squeezed up and the pressure and temperature are both raised all of a sudden. This would mean that should there be a roll surface defect like scratch, pressure and temperature are both increased locally to lead to rupture of the oil film, which in turn would 

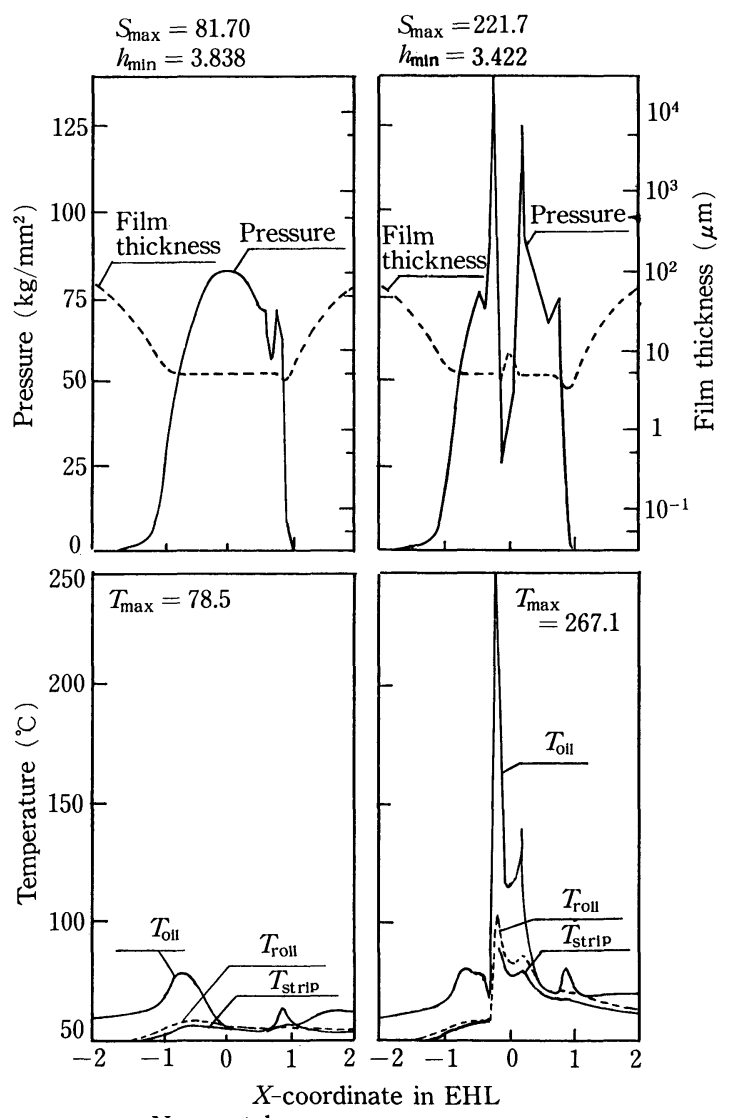

No scratch

$$
\text { Position: } X=0 \quad \text { Depth: } 10 \mu \mathrm{m}
$$

Fig. 21. Effects of dressing scratch on thickness, pressure, and temperature of oil film.

induce seizure.

Furthermore, when the roll surface defect is convex, as in the case of embedded hard particle, the rise of pressure and temperature is at the peak of that asperity, reaching to a value even greater than for the concave defect, and furnishing conditions for the heat streak to occur.

Figure 22 shows the effects of the size of defect on the smallest film thickness, the greatest oil film pressure, and the highest film temperature for the concave and the convex defects.

From those results, it would appear that the remedies for preventing heat streaks should be (A) to make the dressing scratches as small as possible, (B) to forestall invasion of foreign matter, $(\mathrm{C})$ to select or develop an oil having good resistance to pressure and temperature rise yet having excellent lubricity, and (D) to improve the cooling ability of the roll coolant. For those purposes, methods of simulation using Timken tester, four ball tester, ${ }^{28)}$ Bawden tester, ${ }^{29)}$ and research rolling mill ${ }^{30}$ ) are being developed. It is expected that they as well as new mill-clean oils will serve to ease the rolling operation greatly.

\section{Chattering}

The chattering, which is basically a vibration of the mill, presents itself in several different ways over a frequency range of several tens of $\mathrm{Hz}$ to 500 to $600 \mathrm{~Hz}$. Of those, that occurs in the upper half of

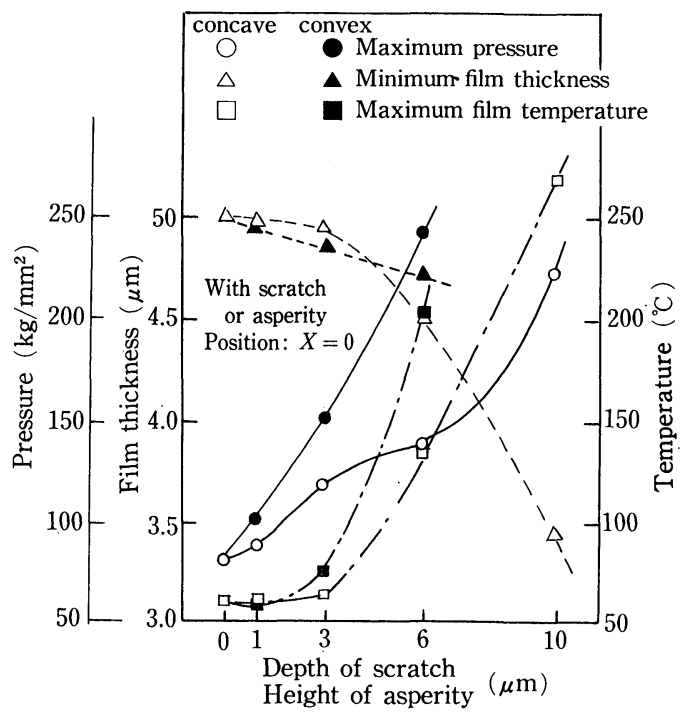

Fig. 22. Effects of size of roll flaw, either concave or convex, on thickness, pressure, and temperature of oil film.

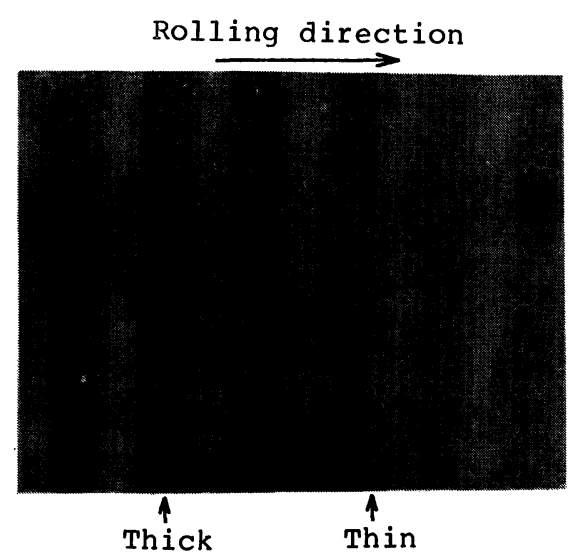

Photo. 3. Appearance of a steel strip rolled when chattering was occurring.

$100 \mathrm{~Hz}$ range is associated with rolling steels of very high flow strengths, such as the thin continuously cast steels, and is considered to be related, directly or indirectly, to the emulsifying properties and the lubricity of the rolling oil. ${ }^{16,31,32)}$ An example is illustrated in Photo. 3, which is an appearance of a steel rolled when the 3 -stand tandem mill was chattering at $190 \mathrm{~Hz}$. The corresponding variation in the steel thickness is shown in Fig. 23. Here, the deviation was as much as $25 \%$, and had the vibration become worse it might well have been the rupture of the strip.

Some practical examples experienced in an operating mill are shown in Fig. 24 for occurrence of chattering in terms of lubrication characterstics of a tallow-base rolling oil, while the aging of an emulsion is illustrated in Photo. 4. It will be noted that chattering is apt to occur either when the emulsion size is too small as just after the start of usage or when it has become too large through aggravation.

In those cases of unsatisfactory emulsification, the friction coefficient estimated on the rolling theory equations is relatively large. When the mill starts 
to chatter, however, the friction coefficient becomes smaller so that the neutral point may even be squeezed out of the roll exit end.

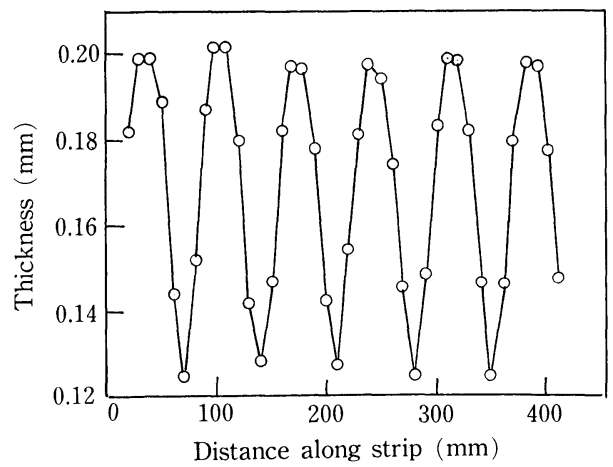

Fig. 23. An example of thickness fluctuation due to chattering.

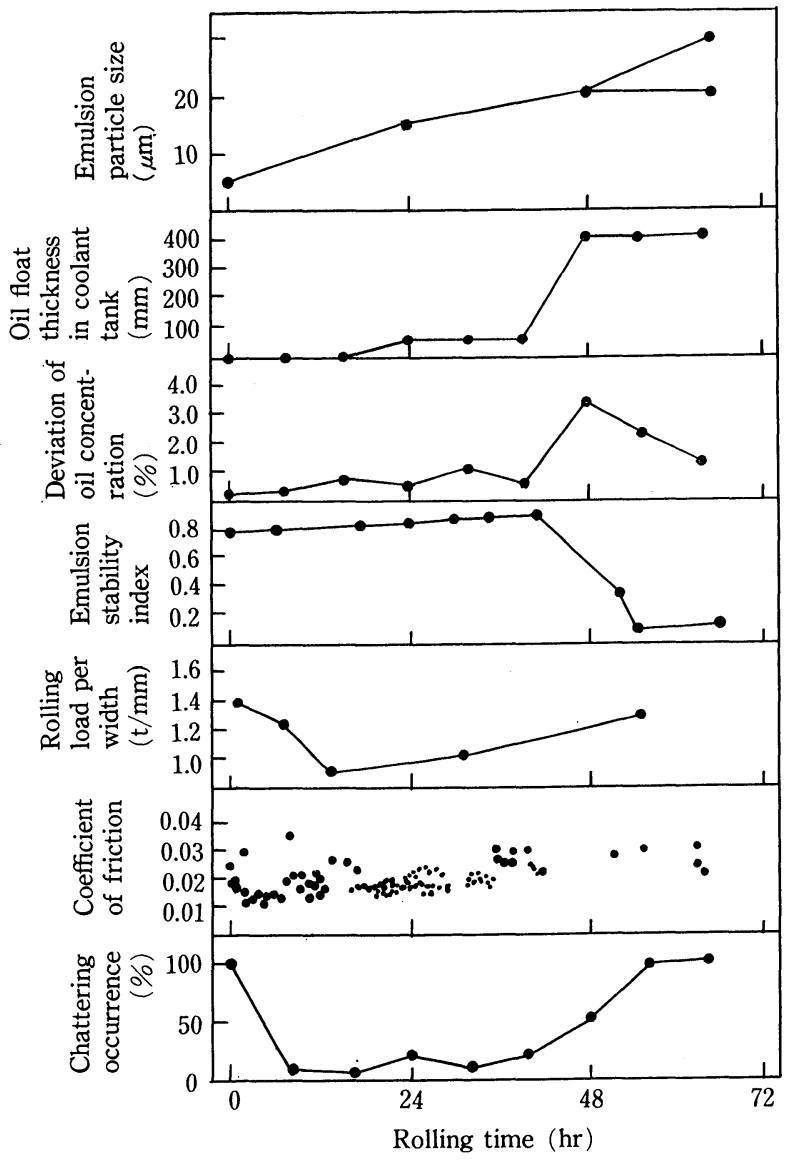

Fig. 24. Effects of emulsion properties of rolling oil on the rolling characteristics and occurrence of chattering.
For chattering that is apt to occur in a certain 6stand tandem mill rolling strips for galvanization using palm oil in the direct application mode upon acceleration and deceleration, it is reported on the basis of actual observation summarized in Fig. 25 that occurrence is more frequent when the friction coefficient becomes lower than a certain limit and when the work temperature is low. ${ }^{33)}$ According to another report, ${ }^{34)}$ furthermore, excessive increase of rolling load can be a cause of chattering also.

As for the vibration analysis of chattering, four models of Fig. 26 are being considered for the mill rolls system..$^{31,34,35)}$ The system natural frequency may be calculated for the 4 mass-spring model by:

$$
\begin{array}{cccc}
\frac{k_{1}+k_{2}}{m_{1}}-\omega^{2} & \frac{-k_{2}}{m_{1}} & 0 & 0 \\
\frac{-k_{1}}{m_{2}} & \frac{k_{2}+k_{3}}{m_{2}}-\omega^{2} & \frac{-k_{3}}{m_{2}} & 0 \\
0 & \frac{-k_{2}}{m_{3}} & \frac{k_{3}+k_{4}}{m_{3}}-\omega^{2} & \frac{-k_{4}}{m_{3}} \\
0 & 0 & \frac{-k_{4}}{m_{4}} & \frac{k_{4}+k_{5}}{m_{4}}-\omega^{2}
\end{array}
$$$$
=0
$$

Figure 27 shows the natural frequencies of roll vibration system of Fig. 26(a) calculated for the mill of Photo. 3 and Fig. 23. It will be seen that the

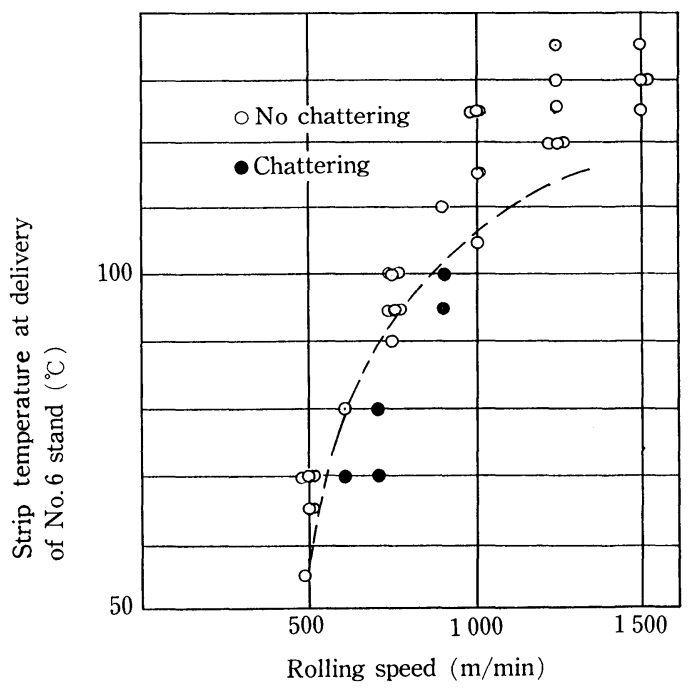

Fig. 25. Effects of rolling condition on occurrence of chattering.

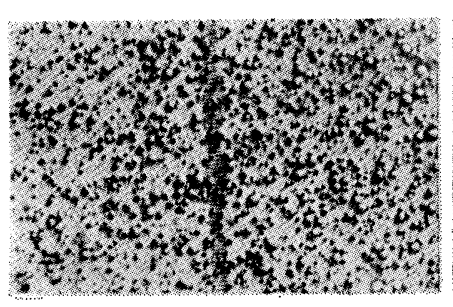

As prepared

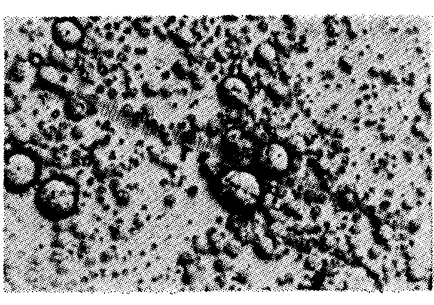

After $24 \mathrm{hr}$

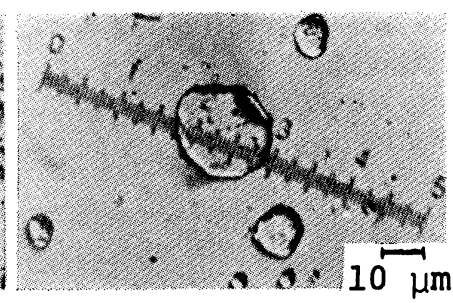

After $48 \mathrm{hr}$

Photo. 4. Aging of an emulsified rolling oil containing phosphoric ester as emulsifier and polarizer. 


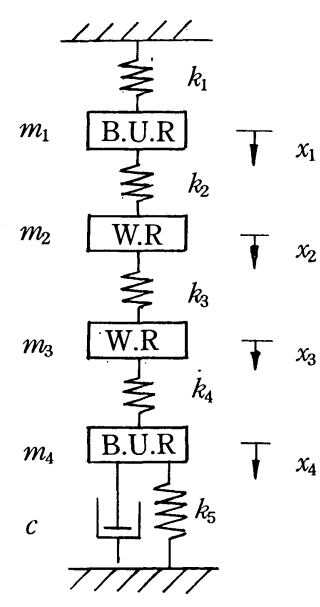

(a) 4 degrees of freedom

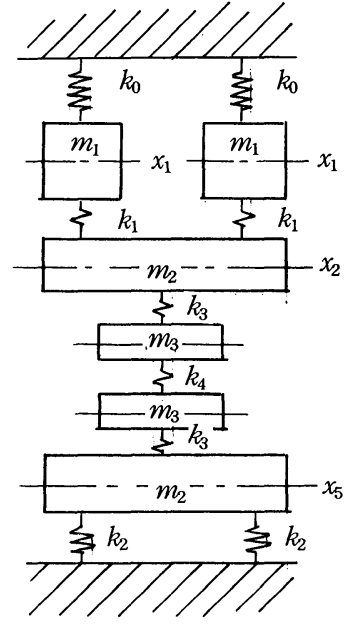

(b) 5 degrees of freedom

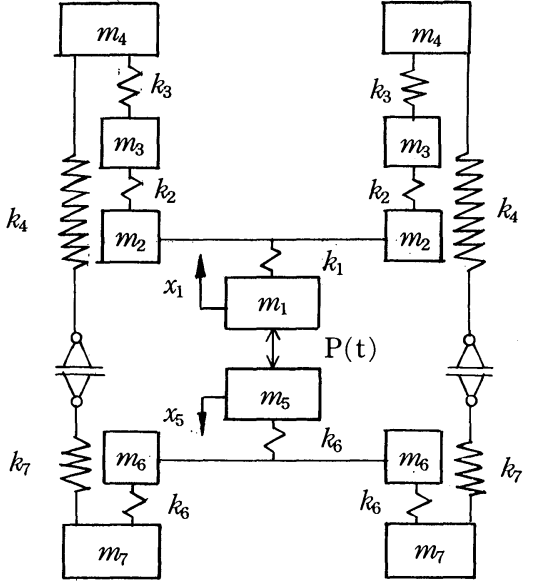

(c) 7 degrees of freedom

Fig. 26. Models of rolling mill vibration for analysis of chattering.

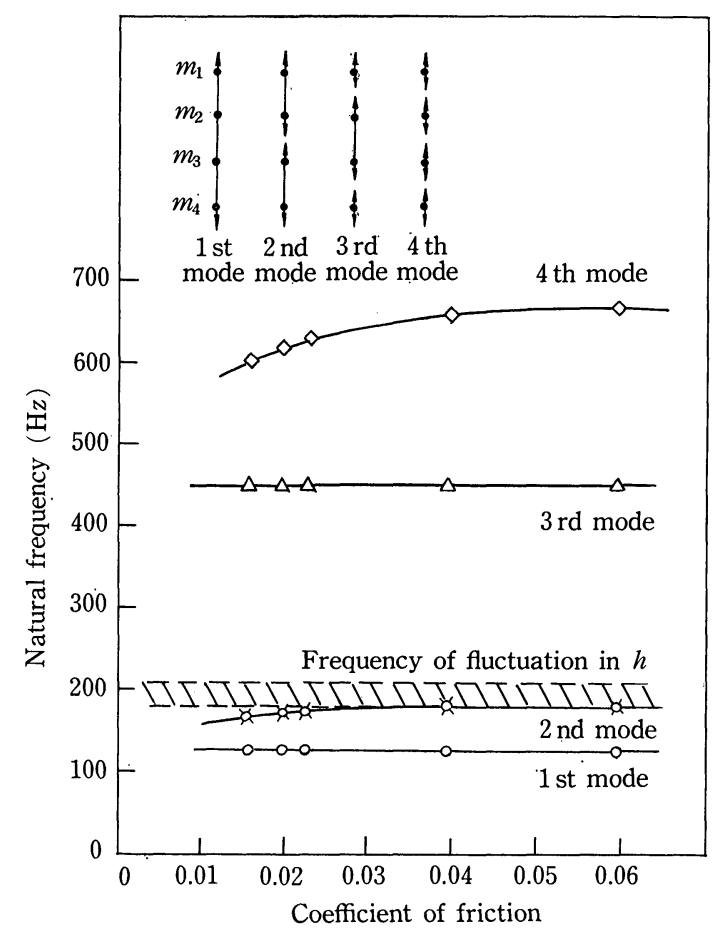

Fig. 27. An example of calculation of natural frequencies conducted on an operating mill with the 4-massspring model.

second order mode vibration, in which the upper and the lower rolls move in mutually opposite directions, is characterized by frequencies that agree with those of plate thickness fluctuation actually observed under chattering condition.

According to the stability analysis with the 4 massspring model, further, it was shown that $\mathrm{C} / \mathrm{C}_{o}>$ $(\Delta k / k)^{2} / 8$. This means that rolling mills having a large damping coefficient and a large mill rigidity are in need. Also necessary will be a means to reduce the rolling plasticity constant.

\section{Slipping}

When cold rolling a steel, slipping may take place between the rolls and the material, often leading to rupturing of the steel. This is generally ascribed to the extraordinary wearing of roll during the early stage of usage, so that the roll surface asperity is decreased lowering the friction coefficient. ${ }^{36-39)}$ This phenomenon, which is particularly manifest when rolling the aluminum killed continuously cast stocks, is considered due to hard $\mathrm{FeAl}_{2} \mathrm{O}_{4}$ and $\mathrm{Mn}_{2} \mathrm{AlO}_{4}$ inclusions, which are present abundantly on the slab surface as demonstrated in Photo. 5 to continually polish up the roll. Therefore, the primary remedy for this trouble is to prevent the formation of those alumina inclusions, for which lowering of the slab heating temperature and decreasing the aluminum content of the steel to soften the oxide particles are reported to be effective. ${ }^{38)}$

Further, actual experiences have it that slipping becomes especially noted when the roll roughness is decreased to near $R a 0.2 \mu \mathrm{m}$. This is verified in Fig. 28, which shows how it is possible to ensure a total rolling life for continuously cast stocks as great as or even greater than that for ingot cast stocks by changing the mean dressing roughness to $3.0 \mu \mathrm{m}$ (No. 16 abrasive) from conventional $0.8 \mu \mathrm{m}$ (No. 46 abrasive). ${ }^{39)}$ Also, it is possible to alleviate the initial wearing by changing the roll material from a $3 \mathrm{Cr}$ to a $5 \mathrm{Cr},{ }^{40)}$ as may be seen in Fig. 29.

\section{Lubrication for Hot Rolling}

It is already 15 years since application of rolling oil to hot strip rolling was first reported. And, in those ten years almost all the Japanese hot strip mills have adopted this practice. However, there is no denying that the theoretical study of mechanisms of hot rolling lubrication is lagging behind that for cold rolling because of the far greater influence of temperature compared with the cases of cold rolling; the studies have been limited to methods of oil application in operational processes, selection of oil, optimization of concentration, and other practical aspects only. Nevertheless, gains in the power consumption and in the roll consumption due to decreased rolling 

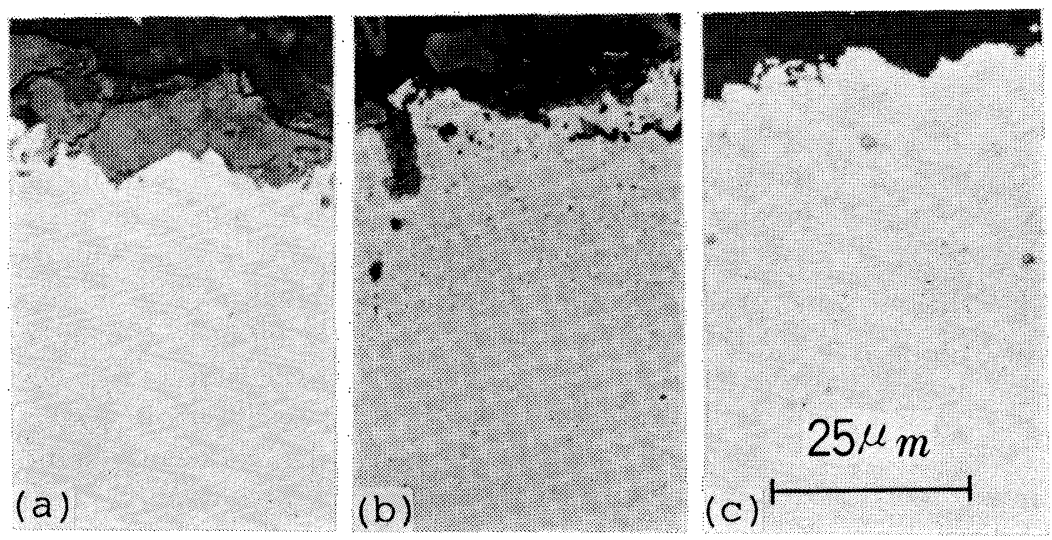

(a) As continuously cast

(b) As reheated to $1220^{\circ} \mathrm{C}$

(c) As reheated to $1140^{\circ} \mathrm{C}$

Photo. 5.

Distribution of oxide particles in near the surface of three different slabs of the same continuous casting charge.

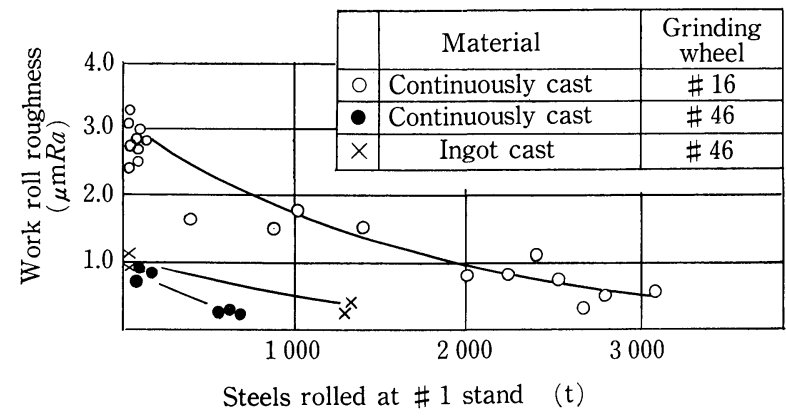

Fig. 28. Difference in the change of work roll surface roughness due to difference in the dressing practice and to the steel.

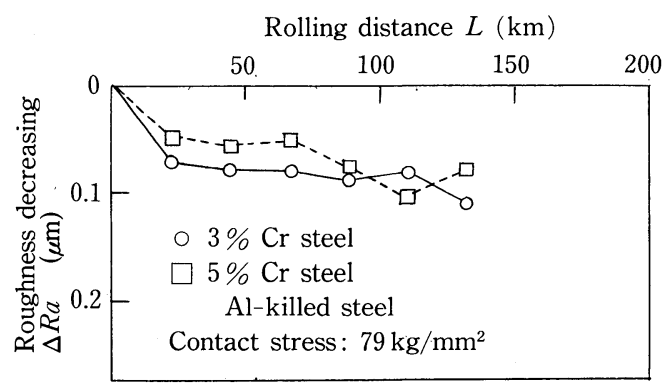

Fig. 29. Effects of $\mathrm{Cr}$ addition on the loss of work roll asperity.

load are already appreciable.

\section{Mechanisms and Effects of Lubrication in Hot Rolling}

At present, the mechanism of hot rolling lubrication is considered to be as follows: a part of the oil that is plated out onto the roll surface is burnt by the heat coming from the material, and is gasified producing combustion products, mostly ash, while the rest is drawn as plated out oil film into the contact arc, both bringing about lubrication effect within a very short time of contact of $1 / 100 \mathrm{sec}$ or so. ${ }^{41)}$

Also, from the experimental results obtained in a small laboratory rolling mill shown in Fig. 30, existence of hydrodynamic lubrication has been deduced on the basis of difference in decrement of mean rolling force between various tallow base rolling oils of different viscosity. ${ }^{42}$ This may suggest that the effects of the number of carbon or the degree of saturation of fatty acids on the boundary layer lubri-

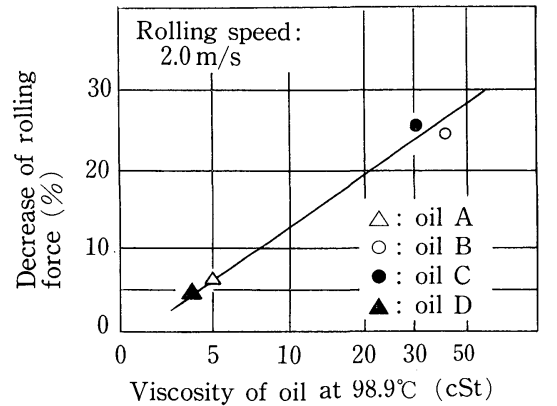

Fig. 30. Effects of viscosity on hot rolling lubrication.

city of tallows are much the same as in the case of cold rolling, e.g., the higher the carbon number, or the more saturated the fatty acid is, the better lubricity one would expect.

Thus, the properties that are required of a rolling oil for hot strip rolling are the easy plating-out, good emulsification, good resistance of not get washed out by coolant, high fluid point, and high fire point. For this, the common oils are the animal or vegetable oil (generally tallows) and the synthetic esters.

The effects of the rolling oil observed are decrease of rolling force, rolling power, and roll wear, and, as the secondary effect, improvement in plate profile and surface quality. ${ }^{43)}$ The decrease of rolling force appears to be related to the material of the roll. That is to say, as may be seen in Fig. $31,{ }^{44)}$ the effect is greater in the fore stands, in which high hardness adamite rolls are used, than in the rear stands; this amounts to as much as 10 to $30 \%$ as compared to the case of no lubrication.

Though the exact mechanism for this is not known, it may well be that at the adamite rolls of fore stands the rolling oil helps to develop the black skin, which is a magnetite type oxide layer, and which is known to have a good lubricity. ${ }^{45}$ As shown in Fig. 32, however, this effect diminishes for oil film thicknesses of over 0.5 to $0.6 \mu \mathrm{m}$. This would mean that only a small quantity of adhered oil should be enough to give rise to a good lubricity. ${ }^{46)}$

The effect on the decrease of roll wear, on the other hand, is great; the wear can be as much as about $30 \%$ of what would have been in the case of no lubrication. This is shown in Fig. 33,45) and figuratively presented by Eq. (25), where it will be noticed 
that the rate of roll wear is subjected indirectly to formation of the black skin.

Rate of roll wear

$\sim\left(\begin{array}{l}\text { Rolling } \\ \text { force }\end{array}\right)\left(\begin{array}{l}\text { Friction } \\ \text { coefficient }\end{array}\right)\left(\begin{array}{l}\text { Contact } \\ \text { time }\end{array}\right)\left(\begin{array}{l}\text { Relative } \\ \text { lubricity }\end{array}\right)$
(Roll hardness)

Further, as illustrated in Fig. 34, the lubrication

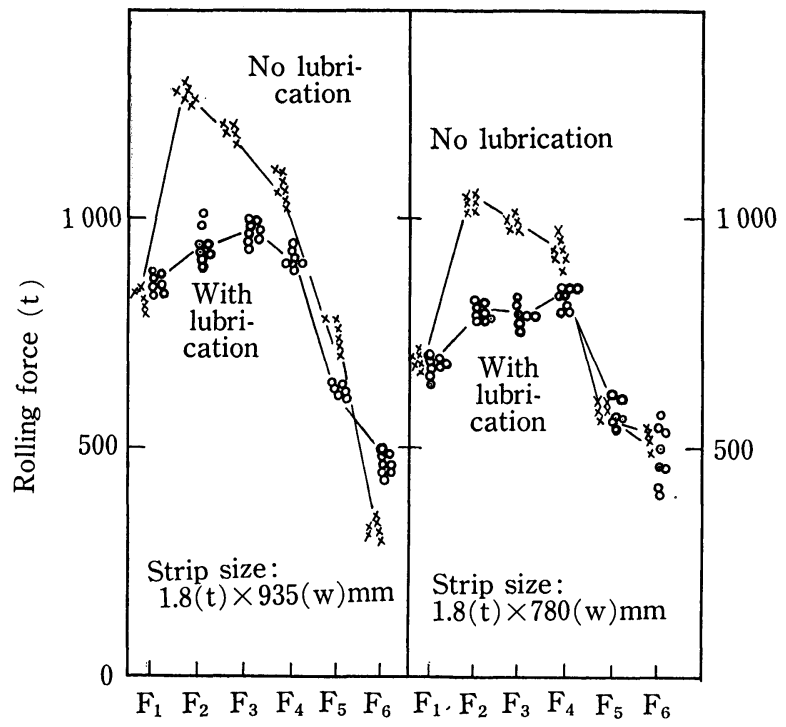

Finisher stands of hot strip tandem mill

$\begin{array}{lllllll}\text { Stand } & \mathrm{F}_{1} & \mathrm{~F}_{2} & \mathrm{~F}_{3} & \mathrm{~F}_{4} & \mathrm{~F}_{5} & \mathrm{~F}_{6} \\ \begin{array}{c}\text { Flow rate of 8.4\% } \\ \text { emulsion }(l / \mathrm{min})\end{array} & 0 & 0.7 & 1.2 & 1.4 & 1.5 & 0\end{array}$

Fig. 31. Decrease of rolling force by application of lubricant in hot strip rolling.

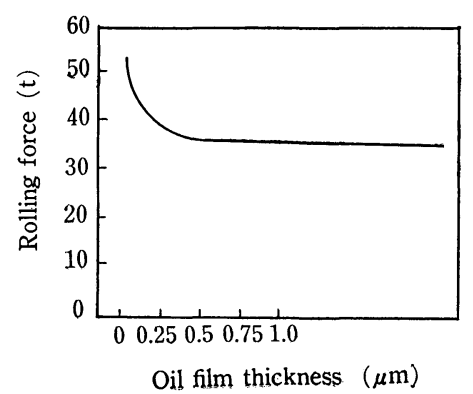

Fig. 32. Relationship between rolling force and oil film thickness.

Oil: tallow

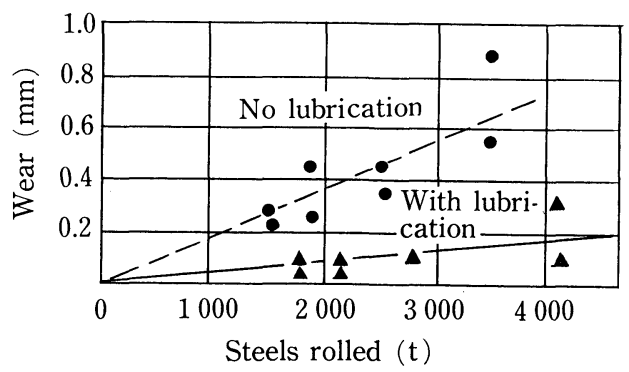

Fig. 33. Effects of lubrication on roll wear. is effective for the roll edge wear also. ${ }^{47)}$ This practice is therefore good to exercise to prevent the roll edges getting worn faster than the middle, a common trouble that occurs because the material temperature tends to be lower, or the resistance to deformation greater, at the edges than at the middle.

The effect on the rolling power is through the decrease in the rolling force. As shown in Fig. 35, this effects can amount to 2 to $10 \%$ in terms of the power consumption rate, which may well cover the cost of the rolling oil. Also, it is known that oil sprayed to a stand affects favorably the following stand, though the effect is no longer felt after that.

The unfavorable effects of applying rolling oil are the slipping at the rollbite, fluctuation in the tension and in the rolling force, occurrence of high spots due to uneven adherence of oil along the width, faulty shape, snaking, and some others. Particularly, to prevent the slipping on-off control of oil application must be done carefully, but, as shown in Fig. $36,{ }^{43)}$ this can be a cause of fluctuation of rolling force and of material thickness. ${ }^{44)}$

\section{Application of Rolling Oil}

One difficulty of applying lubricant that is peculiar to hot rolling is that the oil must be led effectively into the contact arc against the coolant water that is

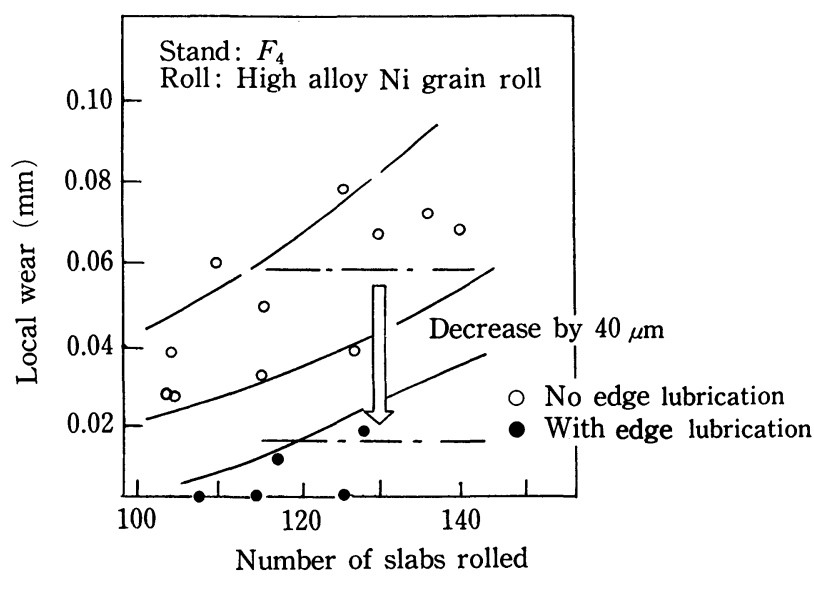

Fig. 34. Effects of rolling with edge oil on roll wear.

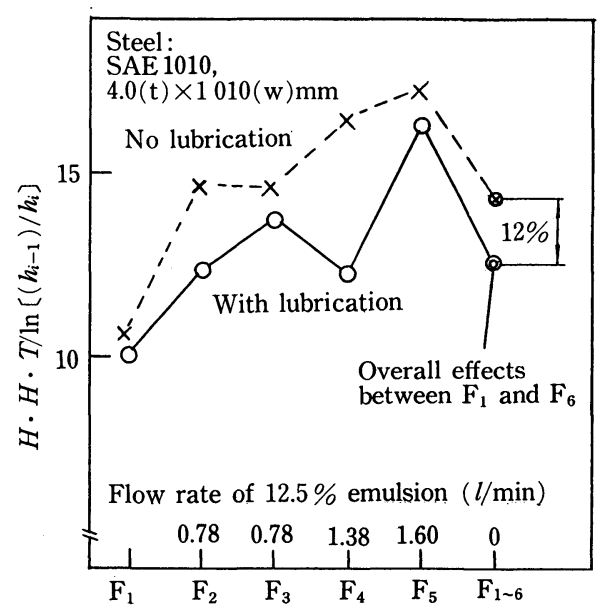

Fig. 35. Effects of lubrication on rolling power. 


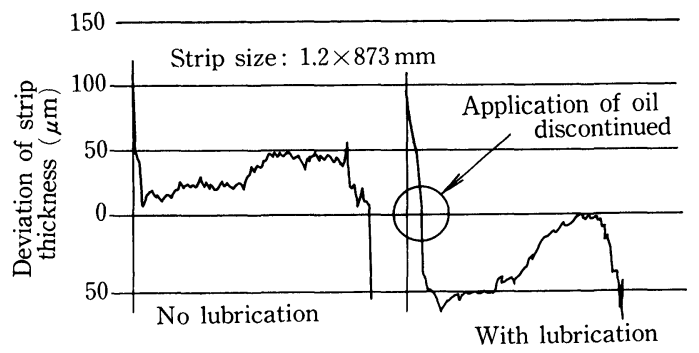

\begin{tabular}{c|cccccc} 
& $\mathrm{F}_{1}$ & $\mathrm{~F}_{2}$ & $\mathrm{~F}_{3}$ & $\mathrm{~F}_{4}$ & $\mathrm{~F}_{5}$ & $\mathrm{~F}_{6}$ \\
\hline $\begin{array}{c}\text { Roll revolution } \\
\text { speed (rpm) }\end{array}$ & 46 & 94 & 172 & 256 & 319 & 366 \\
$\begin{array}{c}\text { Oil feeding rate } \\
\left(\mathrm{cm}^{3} / \text { min) }\right.\end{array}$ & 0 & 25 & 30 & 65 & 75 & 0 \\
$\begin{array}{c}\text { Emulsion feeding } \\
\text { rate }(l / \text { min) }\end{array}$ & 0 & 0.55 & 0.6 & 1.3 & 1.5 & 0
\end{tabular}

Fig. 36. Changes in strip thickness upon stopping of application of rolling oil.

Table 1. Comparison of the three methods of lubricant application for hot rolling.

\begin{tabular}{|c|c|c|c|}
\hline Methods & Injection & Steam atomization & Premixing \\
\hline Features & $\begin{array}{l}\text { 1. Control of emulsion concentra- } \\
\text { tion is easy. } \\
\text { 2. Adherence is good. } \\
\text { 3. Handling is easy. } \\
\text { 4. Waste water treatment is easy. } \\
\text { 5. Equipment cost is low. }\end{array}$ & $\begin{array}{l}\text { 1. Minute oil feeding is possible. } \\
\text { 2. Adherence is good. } \\
\text { 3. Response is good. (Time lag is } \\
\text { small.) } \\
\text { 4. Nozzle clogging is infrequent. }\end{array}$ & $\begin{array}{l}\text { 1. Control of emulsion tempera- } \\
\text { ture and size profile is easy. } \\
\text { 2. Response is good. } \\
\text { 3. Operation is stable. }\end{array}$ \\
\hline $\begin{array}{l}\text { Short- } \\
\text { comings }\end{array}$ & $\begin{array}{l}\text { 1. Minute oil feeding is not very } \\
\text { easy. } \\
\text { 2. Time lag is rather large. } \\
\text { 3. Nozzle clogging is rather fre- } \\
\text { quent. }\end{array}$ & $\begin{array}{l}\text { 1. Controlling of emulsion concen- } \\
\text { tration is critical. } \\
\text { 2. Contact time of emulsion with } \\
\text { steam must be controlled care- } \\
\text { fully. } \\
\text { 3. Equipment cost is high. }\end{array}$ & $\begin{array}{l}\text { 1. Resistance to washing by cool- } \\
\text { ant water is low. } \\
\text { 2. Nozzles apt to clog. }\end{array}$ \\
\hline $\begin{array}{l}\text { Points of } \\
\text { care in } \\
\text { mainte- } \\
\text { nance }\end{array}$ & $\begin{array}{l}\text { 1. Regulation of oil flow-rate. } \\
\text { 2. Frequent inspection of nozzles. } \\
\text { 3. No water to leak from header. }\end{array}$ & $\begin{array}{l}\text { 1. Regulation of concentration. } \\
\text { 2. Regulation of quality and pres- } \\
\text { sure of steam. } \\
\text { 3. Same as left. }\end{array}$ & $\begin{array}{l}\text { 1. Regulation of concentration } \\
\text { 2. Frequent inspection of nozzles. } \\
\text { 3. Same as left. }\end{array}$ \\
\hline
\end{tabular}

being sprayed in a great quantity. This makes the selection of oiling method particularly important in consideration of the operation of the rolling mill.

Typically, there are the water injection method, the steam atomization method, and the premixing method; they are compared in Table 1. As for spraying oil to the roll, this may be done either to the BUR or to the WR. In the former, the oil first adheres onto the BUR, then gets transferred onto the WR to be drawn into the contact arc. In this way, a uniform film can be formed. In the latter, on the other hand, the oil is directly jetted onto the WR, by which a high oil retension may be expected.

To summarize, care should be exercised in selecting one from those methods; it must be done in accordance with the peculiarities of the mill concerned.

\section{Rolls}

In the lowering of rolling cost, increasing of efficiency, and raising of product quality, the contribution of prolongation of roll service life is not to be overlooked. In this chapter, I wish to discuss the cares that should be exercised in selecting rolls for hot rolling or cold rolling and the recent trends in the roll materials development.

\section{Hot Rolling Rolls}

In the hot strip rolling, trends are for hot direct rolling and low temperature extraction for energy saving, high reduction rolling, schedule-free rolling, high pitch rolling, and thin gage rolling for improving the rolling efficiency, and for 6-high mill, WR shift mill and reduction schedule change for better shape and crown control. All those call for stronger, smoother surface, and better economy rolls.

\section{Problems in Usage}

(1) Front Rougher Work Rolls

Right after the slab is extracted from heating furnace, it is the case of high temperature rolling, and the roll surface is heated to as high as $500^{\circ} \mathrm{C}$ upon contact with the slab, becoming down to $20^{\circ} \mathrm{C}$ by coolant. This situation is illustrated in Fig. 37,48) which means that the properties that are demanded of a rougher WR are the high temperature strength and the resistance to this heat cycling.

Also, against fast wearing and chipping off by firecracking, resistivity to wearing is important. ${ }^{49}$ ) Further, because the mill is mostly 2-high, resistivity of the roll to bending is as important as any.

(2) Rear Rougher Work Rolls

Here, the mill is generally 4-high, and the bending strength is not much of a problem for the WR. Rather, resistivity of the roll surface to scale banding is the important consideration, for which heat resistivity to prevent the heat checking is required. ${ }^{49)}$

Other problem areas are wearing, bad biting due to improper selection of the ratio of roll diameter to material thickness or due to slipping, and surface 
depression defects.

(3) Fore Finisher Work Rolls

In the fore stands of the finisher train, the roll surface temperature rises to 400 to $500{ }^{\circ} \mathrm{C}$ as actually determined as in Fig. 38. ${ }^{50}$ Not only that, but the finish rolling schedule often demands heavy reductions at the fore stands, so that the rolling condition is severe thermally and loadwise.

Therefore, resistivity to heat checking and to scale banding is important, as roughened roll is considered to generate chippings and to leave the shooting star marks on the hot coil. ${ }^{51)}$ For this, the admite rolls are generally used.

As for the mechanism of roll surface roughening, many theories such as summarized in Table 2 have
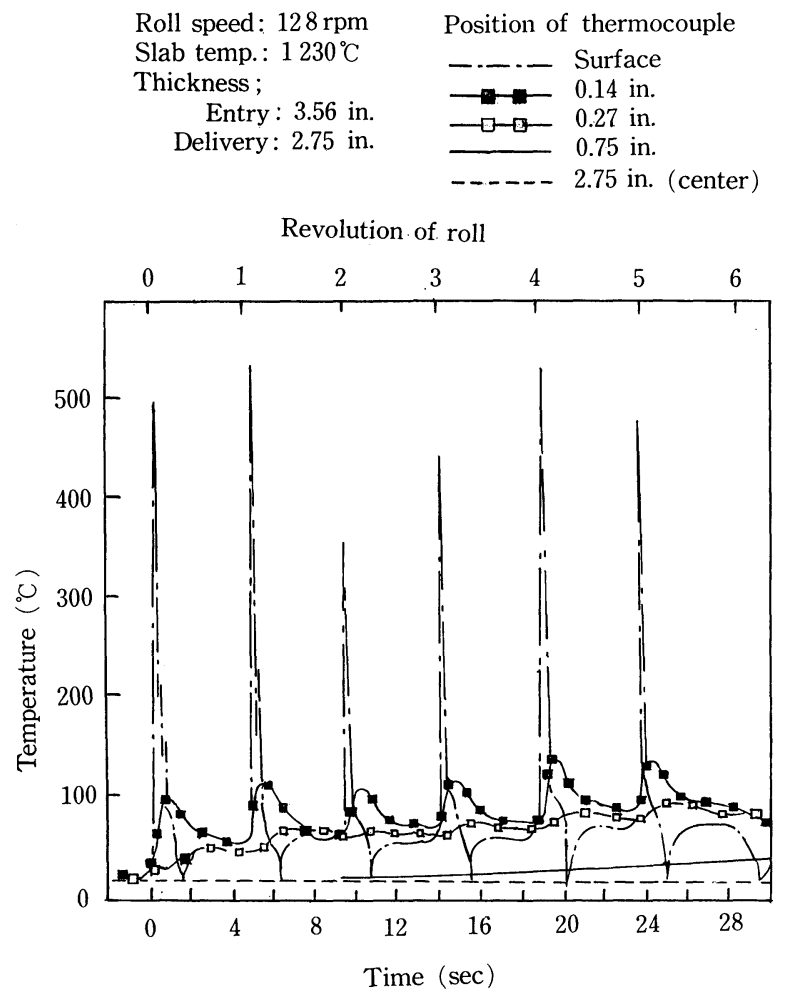

Fig. 37. Changes of the roll temperature as the roll works on the 1st slab. been advanced. Here, it will be seen that they may be divided into two of thoughts. Both take the cracks generated in the roll axial direction to be the direct cause, and one thought ascribes the roughening to the black skin chipping away at those cracks, while the other holds the roll metal itself to be responsible. ${ }^{53)}$ In either case, the cracks have been seen to develop from large carbides of the roll metal under repeated thermal stress and under compressive stress upon contact with the material.

In the black skin theory, the black skin in question, which is an oxide scale of $\mathrm{Fe}_{3} \mathrm{O}_{4}$ formed below $570{ }^{\circ} \mathrm{C}$, is thought to be either the material's scale transferred onto the roll ${ }^{53,54)}$ or the roll itself having been oxidized. ${ }^{51)}$ That is to say, it may be that the scale is formed as illustrated in Fig. 3954) on the material surface in the contact arc by the corrosion reaction due to high temperature, high pressure steam that produces $\mathrm{Fe}(\mathrm{OH})_{2}$ that becomes $\mathrm{Fe}_{3} \mathrm{O}_{4}$ as it is rubbed onto the roll surface. The roll oxidization

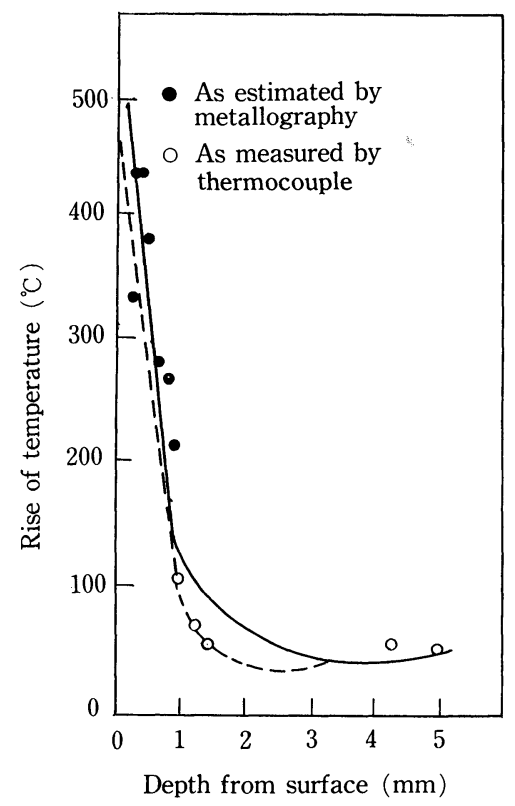

Fig. 38. Temperature distribution near the roll surface determined at a fore finisher stand.

Table 2. Theories for the surface roughening of hot strip tandem mill for finisher work rolls.

\begin{tabular}{|c|c|}
\hline Heat cracking & $\begin{array}{l}\text { Cracks are formed by repeating heating and cooling, into which material's scale is forced; as the scale } \\
\text { particles fall off, they scratch the roll causing banding. }\end{array}$ \\
\hline $\begin{array}{l}\text { Falling off of } \\
\text { graphite particles }\end{array}$ & $\begin{array}{l}\text { With cast iron rolls, graphite particles fall off, where the material's scale is forced into; those defects } \\
\text { spread to become the banding. }\end{array}$ \\
\hline Abrasion by scale & The scale on the material surface abrades the roll surface, roughening it. \\
\hline $\begin{array}{l}\text { Exfoliation of roll } \\
\text { surface }\end{array}$ & $\begin{array}{l}\text { Horizontal subsurface cracks are developed from the heatcracks under shearing stress given rise to by } \\
\text { the BUR, and chip off leaving pits and roughening the roll surface. }\end{array}$ \\
\hline Fusing & $\begin{array}{l}\text { Pits are formed at the crossings of heat cracks and where the carbide particles fell away; the black skin } \\
\text { is peeled off exposing the roll metal, onto which the work is fused to pluck off the roll surface. }\end{array}$ \\
\hline Thermal fatigue & $\begin{array}{l}\text { The surface roughening of } F_{1} \text { rolls is due to spalling caused by rolling thermal fatigue under high tem- } \\
\text { perature and repeating load; the chippings leave the shooting star markings by abrasion wear. }\end{array}$ \\
\hline $\begin{array}{l}\text { Collapsing of roll } \\
\text { surface }\end{array}$ & $\begin{array}{l}\text { The horizontal cracks formed in carbide particles by heat cracking and microscopic thermal fatigue are } \\
\text { connected each other and oxidized; roll surface gets locally collapsed under rolling load. }\end{array}$ \\
\hline Other & Roughening due to corrosion-erosion by the cooling water. \\
\hline
\end{tabular}




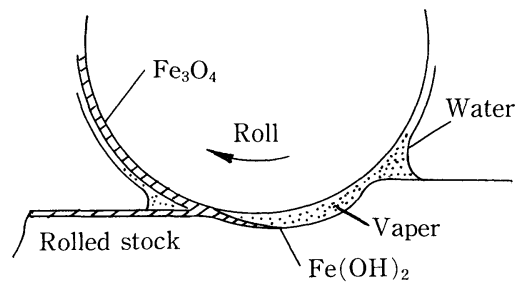

Fig. 39. Mechanism of formation of roll black skin scale by transfer of work surface scale.

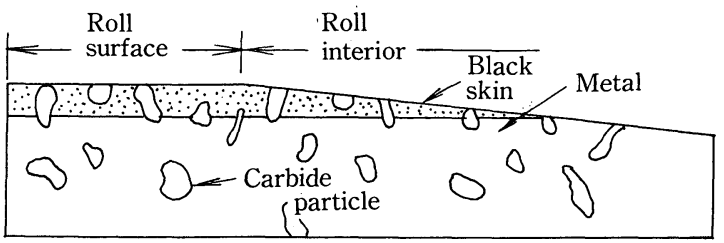

Fig. 40. Mechanism of formation of roll black skin scale by oxidation of roll surface.

theory has it, on the other hand, that the observation shown in Fig. 4051) indubitably supports this view. Namely, right in the black skin that was formed on the roll surface, not only the carbides but $\mathrm{Cr}$ that is an alloying element of the roll are both found contained, indicating the origin to be oxidation of the roll metal itself.

In any case, as the black skin possesses an excellent wear resistivity, how to form and maintain dense and strong black skin quickly and steadily is important for operational practice as well as for selection of the roll materials.

Other properties required of those rolls are the high hardness and high strength under the high temperature, high load condition so that the roll itself may not plastically yield.

(4) Rear Finisher Work Rolls

The resistivity to scale banding is most important as this is directly reflected on the surface quality of the product. Further, to maintain good thickness precision, good profile (small crown, small edge drop, no high spots), and good flatness, resistance to wear must be high. Here, uneven flatness can cause pinching, which may lead to cracking or even breaking of the roll.

To better control the crown and the flatness as well as to achieve greater reduction, 6-high (the HC) mills or WR shift mills are becoming popular for the rear stages of the finisher train in recent years. In the 6-high mills, WRs of 550 to $600 \mathrm{~mm}$ diameter are used, and they are considerably smaller than WRs of ordinary 4-high mills, which are of a diameter 650 to $750 \mathrm{~mm}$. As they are to serve in a rolling condition of greater reduction and higher revolution, hence of a higher load and severer thermal cycle condition, resistivities to contact pressure, bending moment, wearing, and surface roughening must be all high.

The contact pressure distribution between the WR and the intermediate roll in a 6-high mill is shown in Fig. 41.56) The rapid rise of linear load at the step

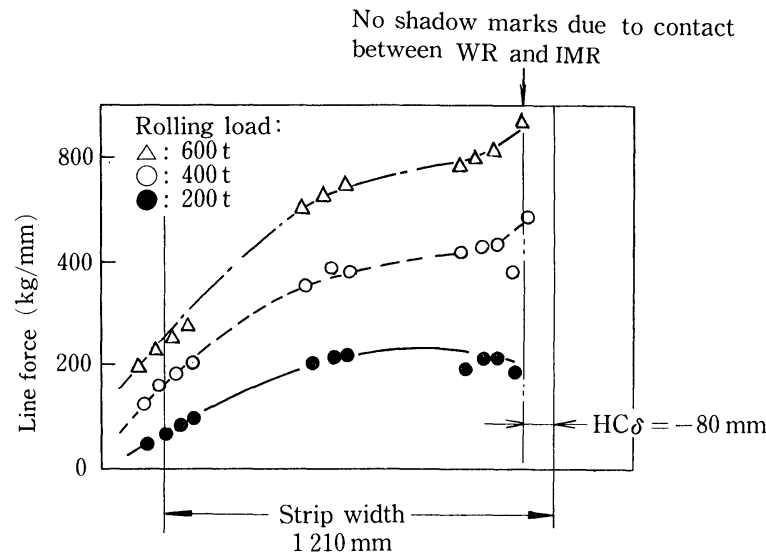

Fig. 41. Distribution of contact pressure between work roll and intermediate roll in 6-high mill working commercially.

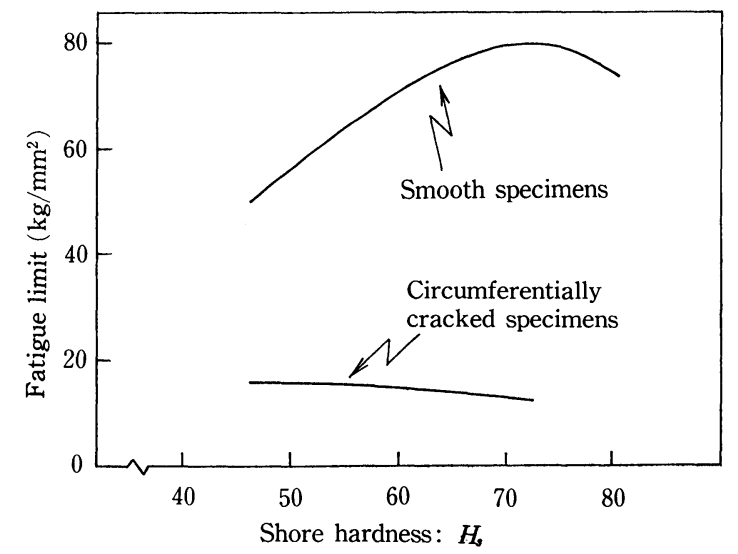

Fig. 42. Relations between hardness and fatigue limit.

part of the intermediate roll may mean localized wear of roll and accumulation of fatigue there. This would suggest that the design of intermediate roll step profile and selection of proper hardness should be important.

\section{(5) Backup Rolls}

For backup rolls in a 4-high mill, which support the rolling load transmitted through the WRs and are subjected to repeated compression force coming through the contact surface with the WRs, resistivities to fatigue, wear, and spalling are important. Figures 42 (hardness vs. fatigue limit), 43 (hardness vs. wear), and 44 (hardness vs. number of revolution to spalling) show that higher hardness should be favored for those properties. However, there are reports that hold high hardness BURs can be a cause of early surface roughening of WRs. ${ }^{56,57)}$ Thus, generally speaking, higher hardness should be preferred when the usage is high load rolling for a long time and normal rolling, but lower hardness should be selected if the rolls have to be used as containing cracks.

Attempts have been made to prevent spalling by alleviating the stress concentration at the BUR shoulder part by providing appropriate chamfer there. ${ }^{57)}$ As may be seen in Fig. 45, chamfering with tapers of less than $0.5 \mathrm{deg}$ or with an arc of more than $500 \mathrm{~mm}$ radius will bring the stress concentration 


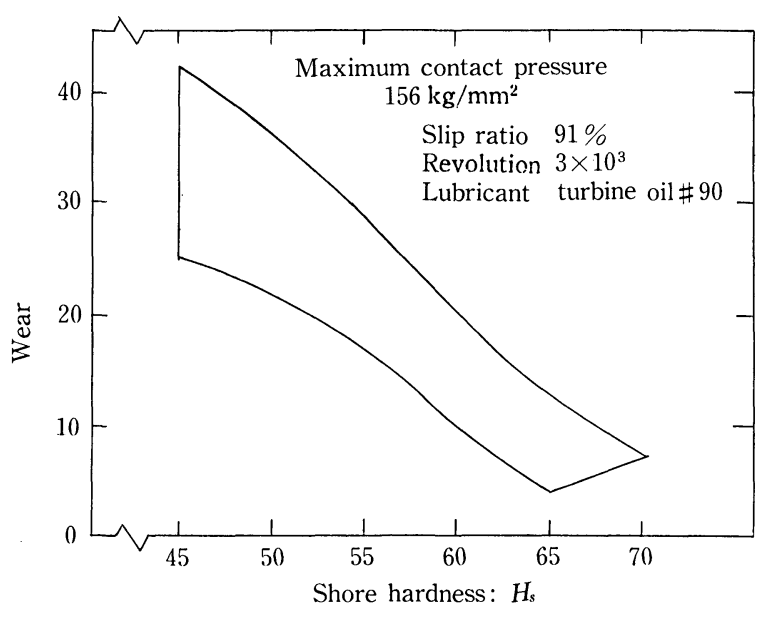

Fig. 43. Relation between hardness and wear.

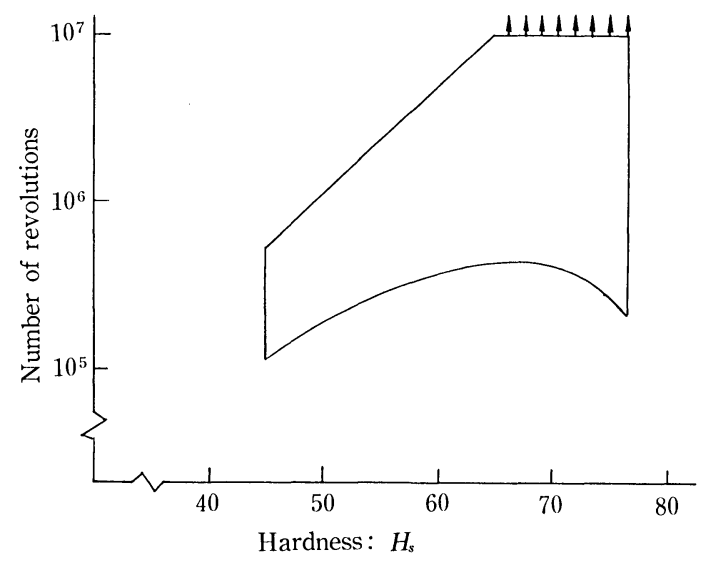

Maximum contact pressure: $175 \mathrm{~kg} / \mathrm{mm}^{2}$ Slip: 0

Lubricant: \#90 turbine oil

Fig. 44. Relation between hardness and spalling life.

down to unity or less.

\section{Trends in Materials for Hot Rolling Rolls}

The foregoing discussions of cares that should be taken in selecting rolls for hot strip rolling may be summarized for considerations on roll materials as follows. ${ }^{49,52,58)}$

\section{(1) Rougher Work Rolls}

Sleeved rolls are becoming popular. For the outer shell, to improve the resistivity to wear and thermal cracking, traditional high $\mathrm{Ni}$ grain cast iron has been superseded by adamite with carbon 1.4 to $1.8 \%$, which is being replaced in turn by high alloy adamite, while the hardness has been raised from 30 to $40 \mathrm{Hs}$ to 40 to $50 \mathrm{Hs}$. In the mean while, the core has been changed from ordinary cast iron to spheroidal graphite cast steel, then high strength tough steel is being experimented.

To keep pace with those developments, the manufacturing method is now centrifugal composite casting rather than old double pour method. Further, the centrifugally casting, sleeve shrink-fitting composite method is being developed.

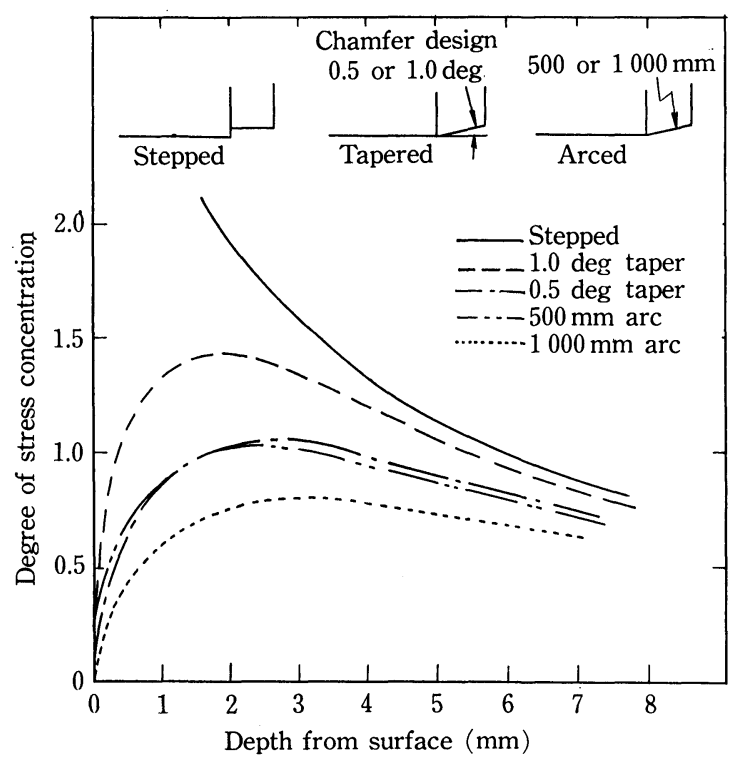

Fig. 45. Effects of chamfer design on stress concentration.

\section{(2) Fore Finisher Work Rolls}

To improve the resistance to surface banding and wearing as well as adhesion of dense black skin, rolls have progressed from high $\mathrm{Ni}$ grain through high hardness (70 to $75 \mathrm{Hs}$ ) alloy grain and alloy ductile to adamite. With respect to the resistance to surface roughening, low carbon adamite is favored for mills of high roll surface temperature, while the high carbon adamite is chosen for those of low temperature services. In either case, the hardness should be 45 to $55 \mathrm{Hs}$, and the granular structure should be one in which an appropriate amount of cementite is uniformly dispersed. The manufacturing method is, in the mean time, being changed from double pour to centrifugal composite.

Here, the recent European development of using high $\mathrm{Cr}$ cast iron rolls of high wear resistivity in mills with more chance of rolling special steels is worth attention. ${ }^{59)}$ The typical chemical compositions and mechanical properties of high $\mathrm{Cr}$ cast iron roll are compared in Table 3 with those of high alloy grain cast iron roll and adamite roll. It appears that no adhesion of black skin occurs for rolling of stainless steels, and that as the hardness of the high $\mathrm{Cr}$ roll itself is high enough the surface heat cracks are made finer, so that a good resistivity to surface roughening is obtained. Moreover, the wear is said to be only $1 / 2$ to $4 / 5$ of that of adamite rolls as shown in Fig. 46 , owing to the uniformly dispersed hard carbide particles, which ensure good high temperature hardness. (3) Rear Finisher Work Rolls

For better resistivity to surface roughening and wear, the roll material has become from high $\mathrm{Ni}$ grain cast iron to high $\mathrm{Ni}$ alloy grain then on to high Ni high alloy grain cast iron. The centrifugal composite casting technique had a great deal to do with densification of the structure and prevention of the hardness decrease.

(4) Backup Rolls

Here, hardening for better resisting wear has been 
Table 3. Ghemical compositions and mechanical properties of high $\mathrm{Cr}$ roll in comparison with those of adamite roll and alloy grain roll.

\begin{tabular}{|c|c|c|c|c|c|c|c|c|c|c|c|c|c|c|}
\hline & \multicolumn{9}{|c|}{ Chemical composition (\%) } & \multicolumn{5}{|c|}{ Mechanical properties } \\
\hline & C & $\mathrm{Si}$ & $\mathrm{Mn}$ & $P$ & $\mathrm{~S}$ & $\mathrm{Ni}$ & $\mathrm{Cr}$ & Mo & Others & $\begin{array}{c}\text { Hard- } \\
\text { ness } \\
(\mathrm{Hs})\end{array}$ & $\begin{array}{c}\text { Tensile } \\
\text { yield } \\
\text { stress } \\
\left(\mathrm{kgf} / \mathrm{mm}^{2}\right)\end{array}$ & $\begin{array}{c}\text { Elastic } \\
\text { modulus } \\
(\mathrm{kgf} / \\
\left.\mathrm{mm}^{2}\right)\end{array}$ & $\begin{array}{l}\text { Com- } \\
\text { pressive } \\
\text { yield } \\
\text { stress } \\
\left(\mathrm{kgf} / \mathrm{mm}^{2}\right)\end{array}$ & $\begin{array}{c}\text { Charpy } \\
\text { impact } \\
\text { value } \\
(\mathrm{kgf-m} / \\
\left.\mathrm{cm}^{2}\right)\end{array}$ \\
\hline $\begin{array}{c}\text { High Cr } \\
\text { roll } \\
\text { (Outer } \\
\text { shell) }\end{array}$ & $\begin{array}{l}2.3 \\
\sim 2.9\end{array}$ & $\begin{array}{l}0.4 \\
\sim 0.5\end{array}$ & $\begin{array}{l}0.8 \\
\sim 1.2\end{array}$ & $<0.04$ & $<0.04$ & $\begin{array}{l}0.5 \\
\sim 1.5\end{array}$ & $\begin{array}{l}13 \\
\sim 18\end{array}$ & $\begin{array}{l}0.7 \\
\sim 2.0\end{array}$ & $\begin{aligned} \mathrm{Nb} & <1.0 \\
\mathrm{~V} & <1.0\end{aligned}$ & $\begin{array}{l}65 \\
\sim 80\end{array}$ & $\begin{array}{l}80 \\
\sim 100\end{array}$ & 21000 & $\begin{array}{l}160 \\
\sim 165\end{array}$ & $\begin{array}{l}0.4 \\
\sim 0.5\end{array}$ \\
\hline $\begin{array}{l}\text { Adamite } \\
\text { roll }\end{array}$ & $\begin{array}{l}1.4 \\
\sim 1.8\end{array}$ & $\begin{array}{l}0.4 \\
\sim 0.8\end{array}$ & $\begin{array}{l}0.8 \\
\sim 1.2\end{array}$ & $<0.03$ & $<0.03$ & $\begin{array}{l}0.5 \\
\sim 1.2\end{array}$ & $\begin{array}{l}0.9 \\
\sim 1.5\end{array}$ & $\begin{array}{l}0.3 \\
\sim 0.6\end{array}$ & - & $\begin{array}{l}50 \\
\sim 57\end{array}$ & $\begin{array}{l}65 \\
\sim 85\end{array}$ & 20000 & $\begin{array}{l}50 \\
\sim 55\end{array}$ & $\begin{array}{l}1.2 \\
\sim 0.5\end{array}$ \\
\hline $\begin{array}{l}\text { High } \\
\text { alloy } \\
\text { grain roll }\end{array}$ & $\begin{array}{l}3.2 \\
\sim 3.4\end{array}$ & $\begin{array}{l}0.7 \\
\sim 0.9\end{array}$ & $\begin{array}{l}0.5 \\
\sim 0.8\end{array}$ & $<0.08$ & $<0.06$ & $\begin{array}{l}4.2 \\
\sim 4.6\end{array}$ & $\begin{array}{l}1.5 \\
\sim 1.9\end{array}$ & $\begin{array}{l}0.3 \\
\sim 0.6\end{array}$ & - & $\begin{array}{l}75 \\
\sim 83\end{array}$ & $\begin{array}{l}40 \\
\sim 50\end{array}$ & 19000 & $\begin{array}{l}160 \\
\sim 170\end{array}$ & $\begin{array}{l}0.25 \\
\sim 0.3\end{array}$ \\
\hline
\end{tabular}

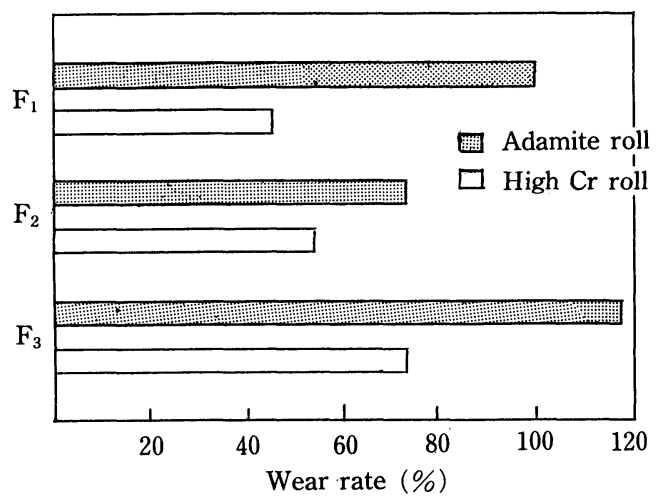

Fig. 46. Comparison of high Cr roll and adamite roll with wearing rate in cold rolling.

stressed, whereby hardness is now 60 to $70 \mathrm{Hs}$ from what used to be 45 to $55 \mathrm{Hs}$. In the single solid rolls, this has been achieved by heat treatment technique both for the composite cast steel and the composite forged steel rolls, while in the sleeved rolls, by devising hard sleeves. For the latter, the problem of sleeve cracking of conventional type has been overcome by developing the high alloy forged sleeve, whose outermost layer only is hardened, retaining toughness in the inner layer. Also, a composite sleeve roll, whose sleeve is composed of a high alloy, high hardness outer shell and a tough cast steel inner shell, has been developed.

\section{Cold Rolling Rolls}

The recent trends in the cold strip rolling are for thicker work, thinner product, more of continuously cast stock, heavier reduction, higher load rolling, more extensive concatenation, toward the schedule-free operation, and better surface quality for the product. All those call for smaller diameter work rolls having longer service life.

\section{Problems in Selection}

In the trend of having to take more and more continuously cast stocks, demand for further improving the wear resistivity is very acute. This is especially so for preventing the slipping due to excessive wear discussed in Section V. 3. That is to say, as the flow

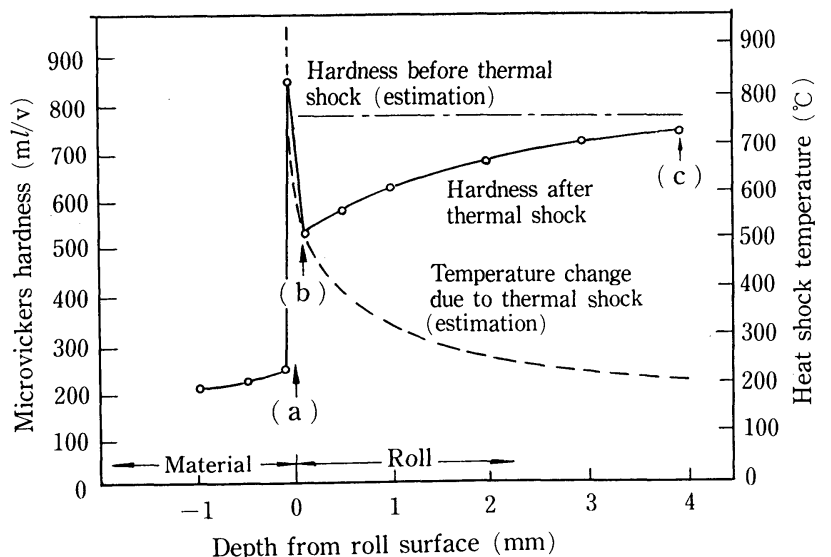

Fig. 47. Changes of hardness of a spalled flake.

stress of continuously cast steels is more than $10 \%$ higher than that of ingot cast stocks, the load on rolls becomes that much higher, inducing greater wearing and faster dulling of surface. In fact, as was shown in Fig. 28, though the initial wearing is fast both for continuously cast stock and for ingot cast stock alike, subsequent decrease in the surface asperity is far greater for the continuously cast stocks.

Also important is the insusceptibility to abnormal rolling, namely that property of a roll which guards the roll from getting fatally damaged by spalling and flaking and such even when accidents like slipping, pincher marking, or breaking of coil did happen. In those accidents, it is said that the friction heat or plastic deformation heat could raise the roll surface temperature to above the transformation point, ${ }^{60}$ ) so that this thermal impact could change the microstructure, hardness, and state of residual stress of surface to give rise to a tensile stress which induces heat cracking. ${ }^{61)}$ Figure 47 shows a hardness distribution determined for a spalled flake. It will be seen that there are a re-quenched layer right beneath the surface and a high temperature tempered zone underneath of it.

It is well known also that localized excessive wearing or spalling occur very often in that part of the roll that worked the ears of Al-killed continuously 


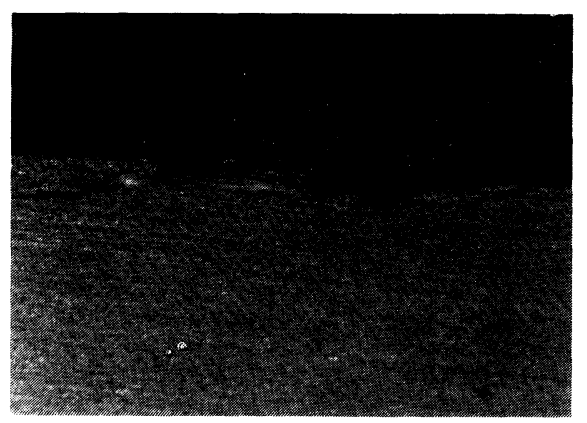

Photo. 6. Cracks generated right beneath an overlap.

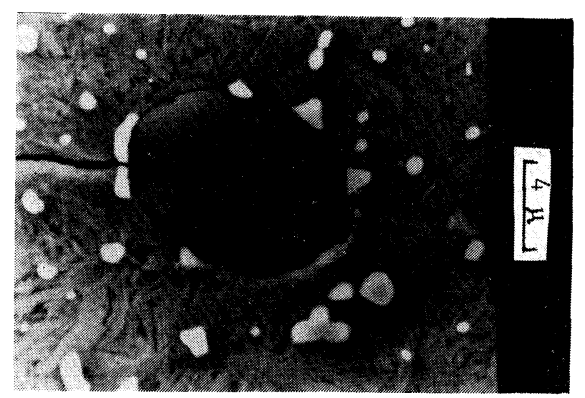

Photo. 7. Cracks originated from an inclusion found at $0.18 \mathrm{~mm}$ beneath the surface.

This kind of cracks disappears at about $0.7 \mathrm{~mm}$ deep.

cast stock intended for galvanizing. It appears that most of those spallings had originated from cracks induced by seizing such as by heat streaking and left over in the dressing.

In fact, in that portion of roll which was banded from rolling ears numerous micro-scabs of $1 \mathrm{~mm}$ or so are found, and under them cracks are often detected developed parallel to the roll axis. An example is shown in Photo. 6. As may be seen in Photo. 7, further, cracks are found even in portions without those scabs developed parallel to the roll surface starting from nonmetallic inclusions exposed on the roll surface. Those are considered to be the direct cause of spalling. ${ }^{62)}$

What is necessary in the roll selection is, therefore, (1) use of cleaner steels, i.e., those that contain less inclusions, and (2) manufacturing so as to leave as little compressive stress as possible; while, in the rolling operation side, (1) lowering of rolling load, e.g., low FDT (Finisher Delivery Temperature) rolling in hot rolling, and (2) improving of lubrication and cooling of rolls.

For improvement of product surface quality, on the other hand, surface roughening like that illustrated in Fig. 48 should be carefully watched. The difference in resistivity to surface roughening is considered due to difference in the interdendritic concentration, ${ }^{61)}$ such that when the dendrite pattern is along the roll circumference direction, this pattern may be erased by temper rolling using dulled rolls, but when it is in the roll axis, the pattern will persist after temper rolling. ${ }^{62)}$ For this, refinement of dendritic structure as well as correction of the dendrite

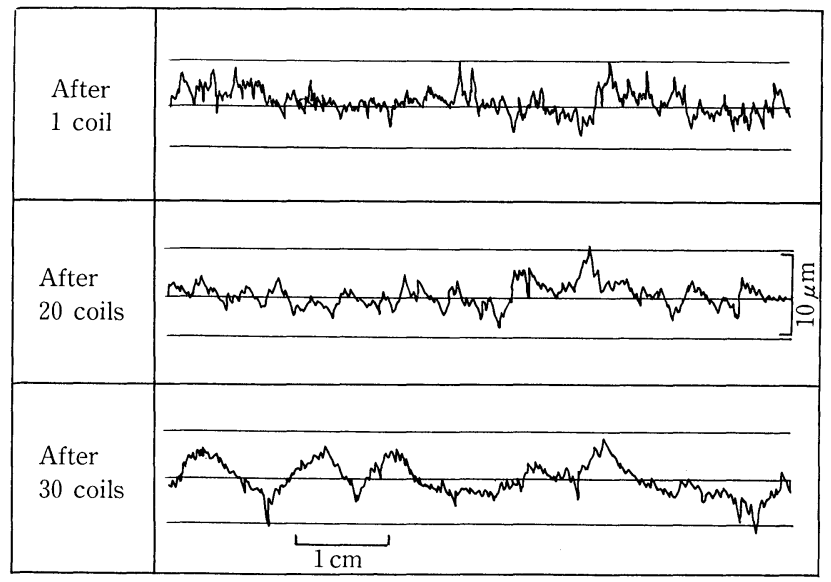

Fig. 48. Changes in the roll surface profile as the progress of service.

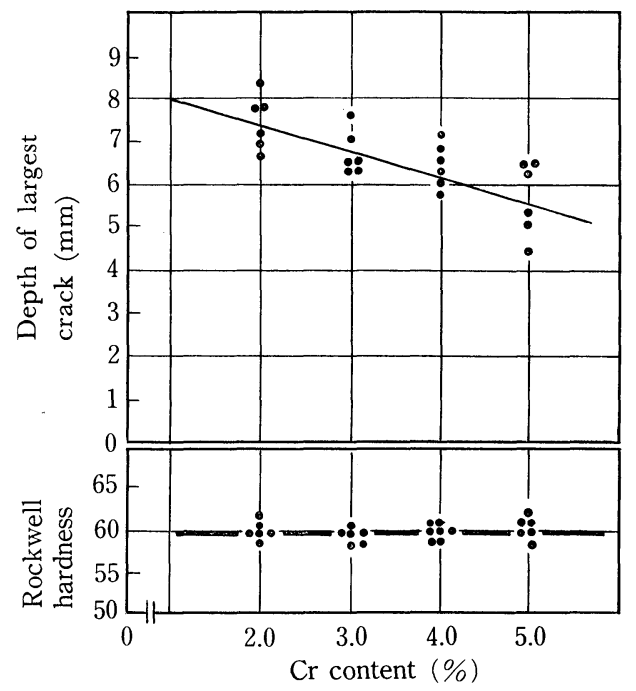

Fig. 49. Effects of $\mathrm{Cr}$ content on resistivity to cracking (0.90C-0.50Si-0.31Mn-2 5 $\mathrm{Cr}$ steel, heated by friction).

pattern is necessary.

The requirements for the backup rolls are elimination of eccentricity for better precision of product thickness and high hardness and better wear resistivity for concatenated rolling practice as well as for prolongation of roll life. Those for the 6-high mill are similar to those for hot rolling rolls, among which the resistance to static pressure acting between the work roll and the intermediate roll is of a particular importance.

\section{Trends of Progress of Cold Rolling Rolls}

For work rolls, conventional $0.8 \mathrm{G}-1.18 \mathrm{Cr}$ type forged steel rolls are being replaced with 3 or more Cr steels, containing further V, Ti and other alloying elements. This is because to improve the wear resistivity, the amount and the hardness of carbides have both to increase. As may be seen in Fig. 49, further, increase of $\mathrm{Cr}$ content is beneficial for improving the resistance to cracking, thus alleviating the susceptibility to abnormal rolling. Also, addition of $\mathrm{Si}$ and $\mathrm{Co}$ is said to be effective.60) Another effect of $\mathrm{Cr}$ is seen in the refined dendritic pattern, which 


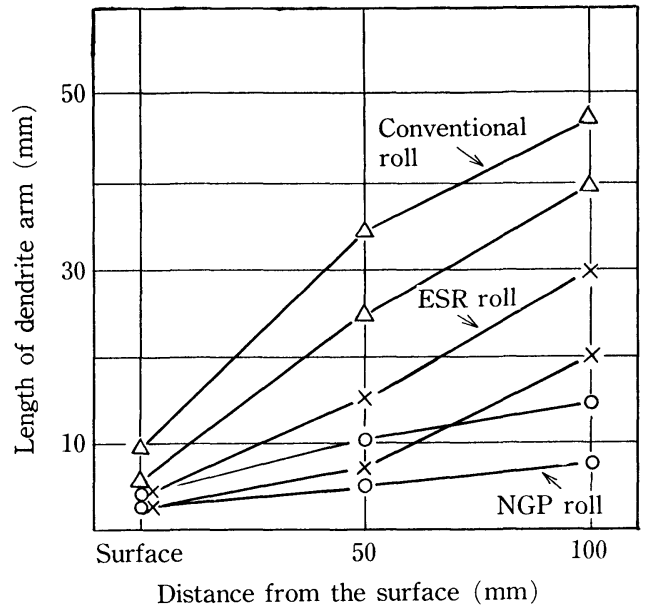

Fig. 50. Relations between distance below surface and length of dendrite $\operatorname{arm}(598 \mathrm{~mm} \phi$ roll, $0.8 \mathrm{C}-3.0 \mathrm{Cr}-$ 0.3 Mo steel).

helps improve the resistivity to surface roughening.

As for the manufacturing method, the vacuum arc remelting process (VAR) and the electroslag melting process (ESR) have contributed greatly to improving the surface cleanness and the internal structural soundness by markedly decreasing the nonmetallic inclusions. Particularly, the ESR method is known to give rise to a dense solidification structure by the virtue of its characteristic low solidification rate, and, by adopting diffusion treatment further, yet better surface roughening resistivity may be obtained. In recent years, moreover, a special ingot making process called the NGP (Non-ghost Process) has been developed. This method is said to be able to refine and homogenize the dendritic structure particularly well and deep into the core, as shown in Fig. 50.60)

In the heat treatment technique, besides the quench hardening effect of Cr itself, the dual frequency induction heating method and the low frequency heating method have progressed. Those have, when applied in conjunction with the subzero treatment, enabled the hardened zone to extend more deeply and the surface compressive residual stress and the internal tensile residual stress both to be alleviated considerably to improve the insusceptibility to abnormal rolling.

Recent changes in the requirement and attending changes in the material and manufacturing method of cold rolling work roll are summarized in Fig. 51.60)

For the backup rolls, which come in either the solid roll or the sleeved roll, high hardnesses of above Hs 65 are being demanded. For this purpose, increase of $\mathrm{Cr}$ content and addition of $\mathrm{Mo}$ or $\mathrm{V}$ are being practiced to ensure good toughness in the high hardness range and, for that, to make the high temperature tempering possible.

\section{Conclusions}

In the above, I have discussed the progresses achieved so far and trends seen at present in the lubrication and roll making for thin gage steel rolling.

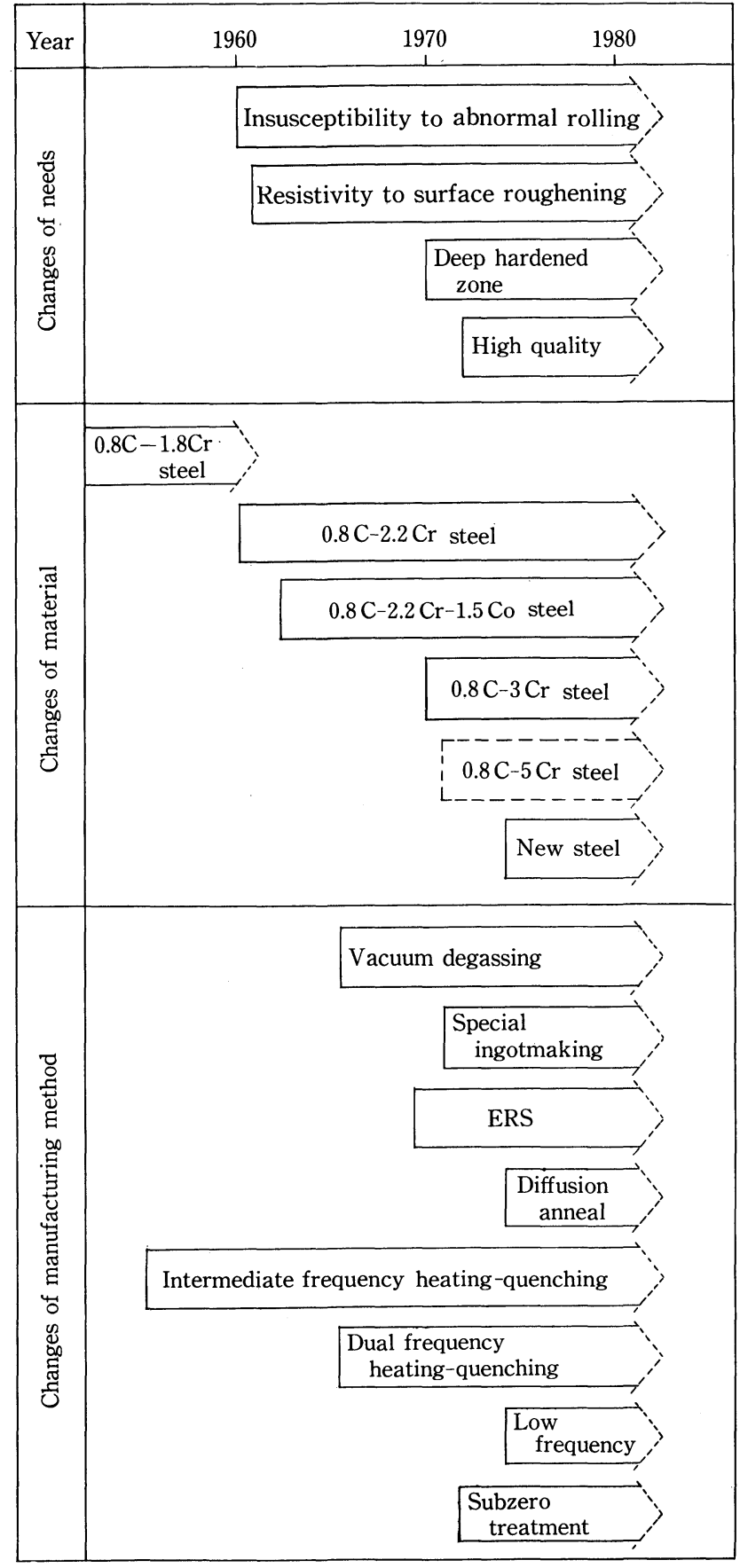

Fig. 51. Changes of needs, material, and manufacturing method for cold rolling work roll.

We have seen that how advances were obtained by challenging those boundary area problems from various approaches like metallurgy, chemistry, rolling theory, lubrication theory, and operating techniques.

In the recent trend of moving toward yet severer rolling conditions through raising the rolling speed, giving heavier reduction and reducing the work roll diameter, in spreading of crown controlling and shape controlling mills, and by attempts at schedulefree rolling, however, we find many more breakthroughs that we will have to achieve. And in my view the following are among those that will require our more immediate attention: 
1) development of rolls having even greater heat resistivity and wear resistivity both in hot rolling and in cold rolling;

2) development of better cooling technology both for the rolls and for the material in remembrance that this area has been left behind the studies of lubrication but will soon become important as the roll load increases;

3 ) in the field of cold rolling oil, improvement of the mill-clean oils to better lubricity, cleansing, and cooling and development of self-lubricating rolls as well as water lubrication on pretreatment of rolls with coating;

4) in the lubrication area, not only for the sake of reduction of rolling load but development of an integrated technology that considers shape and crown control and prevention of snaking; and

$5)$ in the rolling theory, establishment of temperature distribution computation method covering all of the material, rolling oil, and rolls.

I hope that this lecture will contribute to future advancement of the rolling technology.

\section{REFERENCES}

1) von Karman: Zeits. ang. Math. Mech., 5 (1925), 139

2) ex., M. D. Stone: Iron Steel Eng., 30 (1953), 61.

3) ex., A. Nadai: Trans. ASME; J. Appl. Mech., 6 (1939), 54.

4) H.S. Cheng: Friction and Lubrication in Metal Processing, ASME, Ohio, (1966), 69.

5) Y. H. Tsao and L. B. Sargent: ASLE, 21, (1977), 1.

6) E. Orowan: Proc. Inst. Mech. Eng., 150 (1943), 140.

7) D. R. Bland and H. Fard: Proc. Inst. Mech. Eng., 159 (1948), 144.

8) R. B. Sims: JISI, 170 (1954), 19.

9) Tamano and Yanagimoto: J. Japan Soc. Tech. Plasticity, 16 (1975), 87.

10) W.R.D. Wilson and J.A. Walowit: Trans. ASME; J. Lub. Tech., 93 (1971), No. 1, 69.

11) T. A. Dow and S. S. Bupara: Battlle Labs., Report (Private Material), (1974).

12) Nakajima, Shibata and Uehori: the 1977 Japanese Conf. for the Technology of Plasticity, Japan Soc. Tech. Plasticity (JSTP), Tokyo, (1977), 189.

13) Seino, H. Spikes and A. Cameron: Tetsu-to-Hagané, 67 (1981), S385.

14) T. A. Dow and J. W. Kannel: Trans. ASME; J. Lub. Tech., 97 (1975), No. 1, 4.

15) Matsushita, Takatsuka and Matsui: Proc. the 31st Japanese Joint Conf. for the Tech. of Plasticity, Japan Soc. Tech. Plasticity, Tokyo, (1980), 475.

16) Furukawa, Yarita, Seino, Takimoto, Habari, Nakagawa and Fukunaga: Kawasaki Steel Tech. Report, 8 (1976), 60.

17) Furukawa and Kurihara: Tetsu-to-Hagané, 63 (1977), S698.

18) Nagamori, Mukai, Kuwamoto, Iwado and Jinma: Tetsuto-Hagané, 69 (1983), S380; Trans. ISIJ, 23 (1983), B341.

19) Iwado, Kuwamoto and Katayama: Tetsu-to-Hagané, 69 (1983), S381; Trans. ISIJ, 23 (1983), B342.

20) Suzuki, Sunami, Yamaguchi, Furukawa, Seino and Kurihara: Proc. the 30th Japanese Joint Conf. for the Tech. of Plasticity, Japan Soc. Tech. Plasticity, Tokyo, (1979), 65.

21) Kenmochi, Nakagawa, Matsuda, Matsumoto, Matsuda and Nagamori: Tetsu-to-Hagané, 69 (1983), S382.

22) Mase, Yamamoto, Kuwayama and Nishino: Tetsu-to-
Hagané, 69 (1983), S383.

23) Kitamura, Yarita, Nakagawa, Aoki, Matsuda and Sakagami: Tetsu-to-Hagané, 65 (1979), A45.

24) Fukuyama, Iwasaki and Nishimura: the 1979 Japanese Conf. for the Technology of Plasticity, JSTP, Tokyo (1979), 383.

25) H. S. Cheng: Proc. 4th Leeds-Lyon Symp. on Tribology, (1977), 71.

26) Kitahama, Yarita, Kitamura, Kataoka and Nakagawa: the 1980 Japanese Conf. for the Technology of Plasticity, JSTP, Tokyo, (1980), 169.

27) Yarita, Kitamura, Kitahama, Kataoka, Nakagawa, Aoki, Matsuda and Yoshida: Tetsu-to-Hagané, 67 (1981), 2152.

28) Ito and Kitamura: Junkatsu (J. Japan Soc. Lubrication Engrs.), 27 (1982), 559.

29) Mase, Yamamoto and Nishino: Junkatsu (J. JSLE), 27 (1982), 552.

30) Hosono: Junkatsu (J. JSLE), 27 (1982), 588.

31) Yarita, Furukawa, Seino, Takimoto, Nakazato and Nakagawa: Trans. ISIJ, 18 (1978), 1.

32) Tamiya, Furui and Iida: Proc. Int'l Conf. on Steel Rolling, ed. by ISIJ, ISIJ, Tokyo, (1980), 1191.

33) Suga, Kurata, Date, Ishihara and Ishinaga: the 1981 Japanese Conf. for the Technology of Plasticity, JSTP, Tokyo, (1981), 249.

34) A. Swiatoniowski: J. Mech. Working Tech., 7 (1982/83), 183.

35) Mizonoo: J. Japan Soc. Tech. Plasticity, 21 (1980), 1006.

36) R. Ratte and J. Bouteille: Proc. Int'l Conf. on Steel Rolling, ISIJ, Tokyo, (1980), 885.

37) Kitamura, Kitahama, Yasuda, Tsunoyama, Kuguminato and Yanagishima: Tetsu-to-Hagané, 68 (1982), S1202; Trans. ISIJ, 23 (1983), B63.

38) Yasuda, Tsunoyama, Kitamura, Ito, Kuguminato and Yanagishima: Tetsu-to-Hagané, 68 (1982), S1203; Trans. ISIJ, 23 (1983), B176.

39) Yanagishima, Teshiba, Fujiwara, Kuguminato, Kitamura and Yasuda: Tetsu-to-Hagané, 68 (1982), S1204.

40) Yamada and Sekiguchi: Tetsu-to-Hagané, 69 (1983), S378.

41) The Iron and Steel Handbook, III(1), "Basic Theory of Flat-rolling-plate and Sheet", ed. by ISIJ, Maruzen, Tokyo, (1980), 404.

42) Kihara, Doya, Nakamura and Yoshida: Junkatsu ( $J$. JSLE), 27 (1983), 612.

43) Hachiya, Uzawa, Kawamoto, Oba, Ooka and Ito: Seitetsu Kenkyu, (1972), No. 276, 110.

44) Kamii and Terakado: J. Japan Soc. Tech Plasticity, 17 (1976), 202.

45) Nishizawa, Hase, Mase and Kono: Tetsu-to-Hagané, 61 (1975), A77.

46) Hira, Abe, Nakagawa, Ito and Kobayashi: the 1976 Japanese Conf. for the Technology of Plasticity, JSTP, Tokyo, (1976), 25.

47) Sasada, Terakado, Watanabe, Wakako, Tanda, Fujita and Sugita: Seitetsu Kenkyu, (1981), No. 304, 4.

48) P. G. Stevens, K. P. Ivens and P. Harper: JISI, 209 (1971), 1 .

49) Sekimoto and Fukushima: Hitachi Hyoron, 50 (1968), 553.

50) Takami: Trans. Soc. Instrument and Control Eng., 2 (1966), 33.

51) Soeno, Tamamura, Akahori, Suenaga and Tanaka: Hitachi Hyoron, 50 (1968), 553.

52) Yanaka, Toyama, Ayagaki, Matsuda, Saito, Kimura and Okano: Seitetsu Kenkyu, (1982), No. 308, 104.

53) Tabe and Suzuki: Japan Steel Works Technical Reviere, (1969), No. 26, 3024.

54) Okamoto, Tanaka and Yoshimura: Tetsu-to-Hagané, 61 
(1975), 869.

55) Kajihara, Fujino, Nishi, Yoshimura and Shida: Hitachi Hyoron, 58 (1976), 689.

56) Nakagawa: Hitachi Hyoron, 58 (1976), 837.

57) Nakagawa, Asano, Fukushima and Hoshi: Iron Steel Eng., 59 (1982), 23.

58) The Iron and Steel Hanbook, III(1), "Basic Theory of Flat-rolling-plate and Sheet", ed. by ISIJ, Maruzen, Tokyo, (1980), 408.
59) Hashimoto, Katayama, Funakoshi, Seto, Nakagawa and Nakamura: Kubota Technical Report, 7 (1982), No. 1, 21.

60) Miyazawa: The 81st Plastic Working Symposium, (1982), 23.

61) Hoshi, Yaegashi and Seino: Hitachi Hyoron, 56 (1974), 995.

62) Ikariishi: The 81st Plastic Working Symposium, (1982), 37.

63) Nakagawa: Hitachi Hyoron, 58 (1976), 719. 